\title{
Validity of satellite measurements used for the monitoring of UV radiation risk on health
}

\author{
F. Jégou ${ }^{1, *}$, S. Godin-Beekman ${ }^{1}$, M. P. Corrêa ${ }^{2}$, C. Brogniez ${ }^{3}$, F. Auriol ${ }^{3}$, V. H. Peuch ${ }^{4}$, M. Haeffelin ${ }^{5}$, A. Pazmino ${ }^{1}$, \\ P. Saiag ${ }^{6}$, F. Goutail ${ }^{1}$, and E. Mahé , $^{6, * *}$ \\ ${ }^{1}$ UPMC Univ. Paris 06, Université Versailles St-Quentin, CNRS/INSU, UMR8190, LATMOS-IPSL, Paris, France \\ ${ }^{2}$ Instituto de Recursos Naturais, Universidade Federal de Itajubá, Itajubá, Brazil \\ ${ }^{3}$ Laboratoire d'Optique Atmosphérique (LOA), Université Lille 1 Sciences et Technologies, Villeneuve d'Ascq, France \\ ${ }^{4}$ Météo-France CNRM/GMGEC/CARMA, Toulouse, France \\ ${ }^{5}$ Institut Pierre Simon Laplace, École Polytechnique, Palaiseau, France \\ ${ }^{6}$ Service de Dermatologie Générale et Oncologique, Research unit EA 4339 "skin, cancer, and environment", Faculty of \\ medicine Paris-Ile de France Ouest, University of Versailles-St-Quentin, APHP, Hôpital Ambroise Paré, Boulogne, France \\ *now at: Laboratoire de Physique et Chimie de l'Environnement et de l'Espace, CNRS/INSU, Université d'Orléans, \\ UMR6115, Orléans, France \\ *** now at: Service de Dermatologie, Centre Hospitalier Victor Dupouy, Argenteuil Cedex, France
}

Received: 10 May 2011 - Published in Atmos. Chem. Phys. Discuss.: 21 June 2011

Revised: 24 November 2011 - Accepted: 8 December 2011 - Published: 22 December 2011

\begin{abstract}
In order to test the validity of ultraviolet index (UVI) satellite products and UVI model simulations for general public information, intercomparison involving three satellite instruments (SCIAMACHY, OMI and GOME2), the Chemistry and Transport Model, Modélisation de la Chimie Atmosphérique Grande Echelle (MOCAGE), and ground-based instruments was performed in 2008 and 2009. The intercomparison highlighted a systematic high bias of $\sim 1$ UVI in the OMI clear-sky products compared to the SCIAMACHY and TUV model clear-sky products. The OMI and GOME-2 all-sky products are close to the groundbased observations with a low $6 \%$ positive bias, comparable to the results found during the satellite validation campaigns. This result shows that OMI and GOME-2 all-sky products are well appropriate to evaluate the UV-risk on health. The study has pointed out the difficulty to take into account either in the retrieval algorithms or in the models, the large spatial and temporal cloud modification effect on UV radiation. This factor is crucial to provide good quality UV information. OMI and GOME-2 show a realistic UV variability as a function of the cloud cover. Nevertheless these satellite products do not sufficiently take into account the radiation re-
\end{abstract}

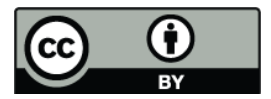

Correspondence to: F. Jégou (fabrice.jegou@orleans.cnrs.fr) flected by clouds. MOCAGE numerical forecasts show good results during periods with low cloud covers, but are actually not adequate for overcast conditions; this is why MétéoFrance currently uses human-expertised cloudiness (rather than direct outputs from Numerical Prediction Models) together with MOCAGE clear-sky UV indices for its operational forecasts. From now on, the UV monitoring could be done using free satellite products (OMI, GOME-2) and operational forecast for general public by using modelling, as long as cloud forecasts and the parametrisation of the impact of cloudiness on UV radiation are adequate.

\section{Introduction}

Ultraviolet light is usually divided into three components (ICNIRP, 2004): UV-A (315-400 nm), UV-B (280-315 nm) and UV-C (100-280 nm). The UV-C component of the solar UV light is potentially the most dangerous as it has the highest energy levels, but this component is completely absorbed by ozone and oxygen above about $30 \mathrm{~km}$. The UV-B component is strongly absorbed by ozone, scattered by molecules, but a small fraction reaches the Earth's surface. The UV-A is weakly absorbed by ozone, with some scattering of radiation near the surface. The biological effects of energy at

Published by Copernicus Publications on behalf of the European Geosciences Union. 
Table 1. CIE action spectrum for erythema.

\begin{tabular}{ll}
\hline$\lambda(\mathrm{nm})$ & $S_{\lambda}$ \\
\hline$\lambda \leq 298$ & 1 \\
$298<\lambda \leq 328$ & $10^{0,094(298-\lambda)}$ \\
$328<\lambda \leq 400$ & $10^{0,015(140-\lambda)}$ \\
\hline
\end{tabular}

these wavelengths are described by different action spectrum functions.

An action spectrum is used as a weighting function for the UV spectrum in an integration of the monochromatic UV irradiance. McKinley and Diffey (1987) proposed an action spectrum for erythema (reddening of the skin due to sunburn) that was adopted as a standard by the International Commission on Illumination (Table 1). This action spectrum stresses the importance of the UV-B component. Of the global UV irradiance at the surface, $94 \%$ is UV-A and $6 \%$ is UV-B. Whereas of the erythemal UV irradiance at the surface, $17 \%$ is UV-A and $83 \%$ is UV-B. An integration over the UV spectrum, weighted with the erythemal action spectrum, provides the erythemal dose rate. The UVI is a dimensionless quantity, where one unit is equal to an erythemal dose rate of $25 \mathrm{~mW} \mathrm{~m}^{-2}$. The UVI is the quantity which is communicated to the general public in connection with warnings of high UV levels (WHO, 2002). Nowadays some instruments on-board satellites (e.g. SCIAMACHY (ENVISAT), OMI (AURA), and GOME-2 (Metop-A)) provide UVI values over the globe at local noon.

The exposure of humans to UV radiation can be beneficial or deleterious according to the received dose. A short exposure (depending of various parameters like latitude, solar zenith angle, absorbing constituents of the atmosphere and exposed skin surface) is essential to synthesize in the skin $25(\mathrm{OH}) \mathrm{D} 3$, the storage form of vitamin $\mathrm{D}$, a hormone necessary for the regulation of the metabolism of the calcium, of bone synthesis, immune regulation and control of cell differentiation and proliferation (McKenzie et al., 2009). On the other hand, overexposure to UV radiation leads to numerous ophthalmological (cataracts, keratitis, macula degenerations) or dermatological (sunburns, photoageing, cutaneous photocarcinogenesis including melanoma, immunosuppression) disorders.

The French RISC-UV project aims to study the link between the observed increase of cutaneous cancers and the variations of UV radiation caused by modifications in the atmospheric composition, and to evaluate the impact of behavioral factors. It leans on the scientific collaboration between a medical community concerned by UV-induced diseases (dermatologists, cancerologists, epidemiologists) and atmospheric physicists interested in the evolution of the surface solar radiation in relation to environmental changes. One of the tasks of the project was to evaluate the consis- tency between UV measurements delivered simultaneously by satellite-based instruments, ground instruments, radiometers and individual dosimeters in the Ile de France region. This evaluation is crucial for the future general public health policies about risks or benefits of UV radiation. Only satellite observations can provide a sufficient spatial and temporal coverage of the global population. Nevertheless, are satellite data accurate enough to help the medical community make public recommendations about UV radiation? The objective of this study is to address this question.

In that context, we compared the UVI measurements provided during the 2008-2009 period by available satellite data to ground-based spectral and broadband UV measurements obtained at the Site Instrumental de Recherche par Télédétection Atmosphérique (SIRTA), located in Palaiseau, France $\left(48.7^{\circ} \mathrm{N} ; 2.2^{\circ} \mathrm{E} ; 170 \mathrm{~m}\right)$. SIRTA is a research facility specialized in measurements of atmospheric constituents and solar radiation (Haeffelin et al., 2005).

The present article shows the results of this comparison exercise, which included also the simulation of the MOCAGE Chemistry and Transport Model from Météo-France. The three following sections describe the satellite, ground-based and model data, respectively. In Sect. 5 the variability of the UV radiation over the SIRTA observatory is evaluated. Section 6 details the comparison of the global databases with the RISC-UV observations. The cloud effect on UV radiation is evaluated in the Sect. 7. A discussion is follows in Sect. 8, about the feasibility of a global satellite monitoring of the UV radiation risk on health.

\section{Satellite data}

\subsection{AURA/OMI}

Aura is the atmospheric chemistry mission of NASA's platform Earth Observing System (EOS) launched on 15 July 2004. Ozone Monitoring Instrument (OMI) is a nadirviewing spectrometer designed to monitor ozone and other atmospheric species (Levelt et al., 2006). OMI covers the wavelength range from 264 to $504 \mathrm{~nm}$. The OMI surface UV algorithm first estimates the clear-sky surface irradiance using the total column ozone measured by OMI, climatological surface albedo, elevation, solar zenith angle, and latitude-dependent climatological ozone and temperature profiles. Next, the clear-sky irradiance is multiplied by a factor that accounts for the attenuation of UV radiation by clouds and nonabsorbing aerosols. The current algorithm (Krotkov et al., 1998, 2001, 2002) does not account for absorbing aerosols (e.g. organic carbon, smoke, and dust) or trace gases (e.g., $\mathrm{NO}_{2}, \mathrm{SO}_{2}$ ), which are known to lead to systematic overestimation of the surface UV irradiance (Chubarova, 2004; Arola et al., 2009) and neglects the cirrus effect on UV radiation. The OMIderived surface UV irradiances are expected to show overestimation for regions that are affected by absorbing aerosols. 
Greatest overestimations are anticipated for regions affected by urban pollution and for major natural aerosol episodes.

The UV irradiances are calculated once a day for local solar noon. Corrections are not made for possible changes in cloudiness or total column ozone between the local noon and satellite overpass time. The OMUVBd (version 3) data product selected are TOMS-like daily L3 gridded (lat-lon $1^{\circ} \times 1^{\circ}$ ) data product. The UVI are provided at the time of overpass and at solar noon for overpass conditions (labelled OMI) and for clear sky conditions (OMI-CS).

To validate the OMI data, comparisons were done with the UV radiation measured in 18 ground-based stations (Tanskanen et al., 2007). For flat, snow-free regions with modest loadings of absorbing aerosols or trace gases, the OMIderived daily erythemal doses have a median overestimation of $0-10 \%$, and some 60 to $80 \%$ of the doses are within $\pm 20 \%$ from the ground reference. For sites significantly affected by absorbing aerosols or trace gases one expects, and observes, bigger positive bias up to $50 \%$ is observed. For high-latitude sites the satellite-derived doses are occasionally underestimated by up to $50 \%$ because of unrealistically small climatological surface albedo.

Intercomparisons were also done with the UV radiation measured in two French sites: Villeneuve d'Ascq and Briançon (Buchard et al., 2008). Comparisons of the erythemal dose rates and erythemal daily doses for clear sky show that OMI overestimates surface UV doses at Villeneuve d'Ascq by about $13 \%$ and that on all sky conditions, the bias slightly increases. At Briançon, such a bias is observed if data corresponding to snow-covered surface are excluded.

In Buntoung et al. (2010) the UVI retrieved from OMI observations and measured from broadband instruments at four sites in Thailand were compared. The comparisons show a positive bias for the OMI data with respect to the groundbased measurements. The differences between the two data sets were $30-60 \%$ for all data and were $10-40 \%$ for cloudless data. The differences for the cleanest site showed better agreement than those for the more urban sites.

\subsection{ENVISAT/SCIAMACHY}

SCIAMACHY (SCanning Imaging Absorption spectroMeter for Atmospheric CartograpHY) is a passive remote sensing spectrometer observing backscattered, reflected or transmitted radiation from the atmosphere and Earth's surface, in the wavelength range between 240 and $2380 \mathrm{~nm}$. The instrument flies on board the ESA ENVISAT satellite which was launched on 1 March 2002. The algorithm used to calculate the UVI (version 1.2) applies a functional relation between this index, the local solar noon ozone fields and the solar zenith angle at local solar noon (Allaart et al., 2004). UV index is provided on a lat-lon $0.5^{\circ} \times 0.5^{\circ}$ resolution. The SCIAMACHY total ozone column is derived from the well-validated data assimilation algorithm described by Eskes et al. (2003). The parametrisation implicitly contains the average aerosol load in De Bilt (The Netherlands) and Paramaribo (Suriname), hence the current method contains a zero-order aerosol correction. The UVI is a quantity valid for local solar noon and for clear-sky conditions.

The daily erythemal UV doses have been validated for Europe through comparisons with ground-based measurement data stored in the European Database for UV Climatology and Evaluation (EDUCE) database (Van Geffen et al., 2005). This database contains UV spectra measured at a large number of European ground stations. Comparisons with the Lampedusa (Italy) and Thessaloniki (Greece) stations show good agreement in clear-sky conditions. A second validation study can be found in De Laat et al. (2010). Measurements from three ground-based stations in the southern tip of South America (Punta Arenas, Chile; Rio Gallegos and Ushuaia, Argentina) are used to validate a three week episode of small total ozone columns and high UV radiation. This study has been achieved from September to December 2009. The regression between observed and modelled UVI shows high correlations $\left(R^{2}\right)$ ranging from 0.8 to 0.94 . Biases are a few percents.

\subsection{Metop-A/GOME-2}

The Meteorological Operational satellite program (Metop) has been jointly established by ESA and the European Organisation for the Exploitation of Meteorological Satellites (EUMETSAT). Launched in October 2006, Metop-A, is the first satellite in a series of three satellites. Surface UVI and daily doses (version 1.3) are derived from the combined measurements of the Metop-A and NOAA satellites (Kujanpää, 2008). The products are calculated in a 0.5 degree regular grid. The total ozone is obtained from the O3M SAF near real time total column ozone product $\left(\mathrm{NTO} / \mathrm{O}_{3}\right)$, derived from the measurements of the GOME-2 instrument on-board Metop-A satellite. The cloud optical depth is estimated from AVHRR/3 channel 1 (visible) reflectances, this instrument being also on-board the Metop-A satellite. The sampling of the diurnal cloud cycle is improved by using additional AVHRR data from the NOAA satellites. Finally, the aerosol optical depth is currently taken from climatology (Kinne, 2007), and the surface albedo from the climatology of Tanskanen (2004). Unfortunately, GOME-2 UVI database is only available from 8 June 2009 and comparisons could be done only for the late period of the RISC-UV2 campaign.

The O3M SAF validation report (Kalakoski, 2009) presents the validation of GOME-2 UV product against ground based UV measurements from 15 different stations and surface UV product based on OMI satellite measurements. Validation was performed for the period starting on 1 June 2007 and ending on 31 May 2008. GOME-2 product generally overestimates the ground-based daily doses, by $10-20 \%$ and show smaller positive biases for the daily maximum dose rates. On the other hand, OMI product is generally 
larger than GOME-2 product with a positive bias of $16.5 \%$ for the daily doses and $9.6 \%$ for daily maximum doses rates.

\section{Ground-based data}

Two field campaigns were organised within RISC-UV. The first campaign (RISC-UV1) was performed between 8 September and 8 October 2008, at the SIRTA observatory. The RISC-UV1 purpose was to obtain, analyse and quantitatively link the UV radiation data obtained at various spatial scales (satellite, ground based and spot measurements) through a variety of measuring systems. Moreover, a set of atmospheric and surface parameters (total ozone column, the vertical profile and optical thickness of aerosols, cloud cover and solar albedo) related to UV radiation was also collected. Measurements were performed in cloudy and clear-sky situations. A second campaign (RISC-UV2) was performed between 18 May and 17 June 2009 at the SIRTA observatory and in eleven different locations in Paris during 4 days with different weather conditions (27-29 May, 2-17 June). This campaign was a new opportunity to compare satellite retrievals and the ground-based UV observations in order to relate different spatial and temporal scales of the UV measurements.

The instrumental setup deployed at the SIRTA observatory consisted of several instruments for: (1) UV radiation measurements (a Bentham spectroradiometer, UV-A, UV-B, Erythemal UV radiometers and broadband solar pyranometers); (2) cloud and aerosol observations (AERONET/Cimel photometer, Lidar and radiometers); and (3) personal monitors for UV index measurements, such as handhelds. The Bentham spectroradiometer is regarded as reference and provides an irradiance scan over the $280-450 \mathrm{~nm}$ wavelength band every fifteen minutes. The scan duration is about $5 \mathrm{~min}$. The Bentham spectroradiometer used in this study is operated by the Laboratoire d'Optique Atmosphérique. It is regularly compared with another instrument that has been checked with the travelling standard QASUME spectroradiometer (Gröbner et al., 2006) and was calibrated at the beginning and at the end of each campaign. Other UV measurements were collected from a set of broadband radiation instruments: a YES UVB-1 pyranometer for measurements of Erythemal effective UV irradiance (UV-E) and UV-B irradiance from 280 to $320 \mathrm{~nm}$; a UVS-AE-T Kipp and Zonen radiometer that measures UV-A irradiance and UV-E; a Solar Light Biometer UVB501 that measures UV-E and UV-B; and handheld Solarmeters UVI dosimeter model 6.5 with a 290-400 nm solar response. The broadband radiometers performed measurements with a 1 min frequency.

\section{Model data}

\subsection{MOCAGE chemistry and transport model}

MOCAGE is a 3-D Chemistry and Transport Model that simulates the interactions between dynamical, physical and chemical processes in the troposphere and lower stratosphere. MOCAGE relies on a semi-Lagrangian advection scheme to transport the chemical species; this scheme is based upon Williamson and Rash (1989) and is evaluated in Josse et al. (2004). MOCAGE includes 47 hybrid $(\sigma, p)$ levels from the surface up to $5 \mathrm{hPa}$. The vertical resolution is 40 to $400 \mathrm{~m}$ in the boundary layer ( 7 levels) and about $800 \mathrm{~m}$ in the vicinity of the tropopause and in the lower stratosphere. The chemical scheme used is called RACMOBUS, which combines the stratospheric scheme REPROBUS (Lefèvre et al., 1994) and the tropospheric scheme RACM (Stockwell et al., 1997). RACMOBUS includes 119 individual species, among which 89 are prognostic variables (family approach), and considers 372 chemical reactions. Surface processes (emissions, dry deposition), turbulent and convective transport, as well as scavenging are explicitly described in the model. See (Bousserez et al., 2007) for more general information on the MOCAGE CTM.

MOCAGE has been used in a range of research studies with over 50 papers in the literature, from air quality (Dufour et al., 2004), to the interpretation of field campaigns (Bousserez et al., 2007) and, for instance, the study of chemistry and climate interactions (Teyssèdre et al., 2007). MOCAGE is also used operationally at Météo-France, in particular in the context of the French Air Quality Platform Prév'Air (Rouil et al., 2008) and of the setting-up of Global Monitoring for Environment and Security (GMES) services for atmospheric composition (Hollingsworth et al., 2008).

For the present study, we have used a configuration of MOCAGE run at a horizontal resolution of $0.5^{\circ}$. The meteorological analyses of Météo-France ARPEGE Numerical Weather Prediction Model (Courtier et al., 1991) have been used to initialize and constrain the dynamics of the model every $3 \mathrm{~h}$ (with linear interpolation in between). The simulations presented here have also assimilated AURA/MLS stratospheric ozone profile information using a variational 3d-fgat method as in El Amraoui et al. (2010).

The UVI calculation in MOCAGE is done with a two-step approach. In a first step, the clear sky UV indices are computed using monthly look-up tables, which are pre-calculated with the TUV model (see Sect. 4.2 below); UV indices are tabulated for a range of values for the solar zenith angle, the ozone profile, the altitude and the UV surface albedo. A simple monthly climatological aerosol extinction is considered to compute the look-up tables, which could induce an overestimation of $\sim 20 \%$ in polluted regions, while the aerosol optical thickness (AOT) is correct for background conditions (Kazadzis et al., 2009). This parametrisation is consistent with the approach for the OMI UVI product for instance. 

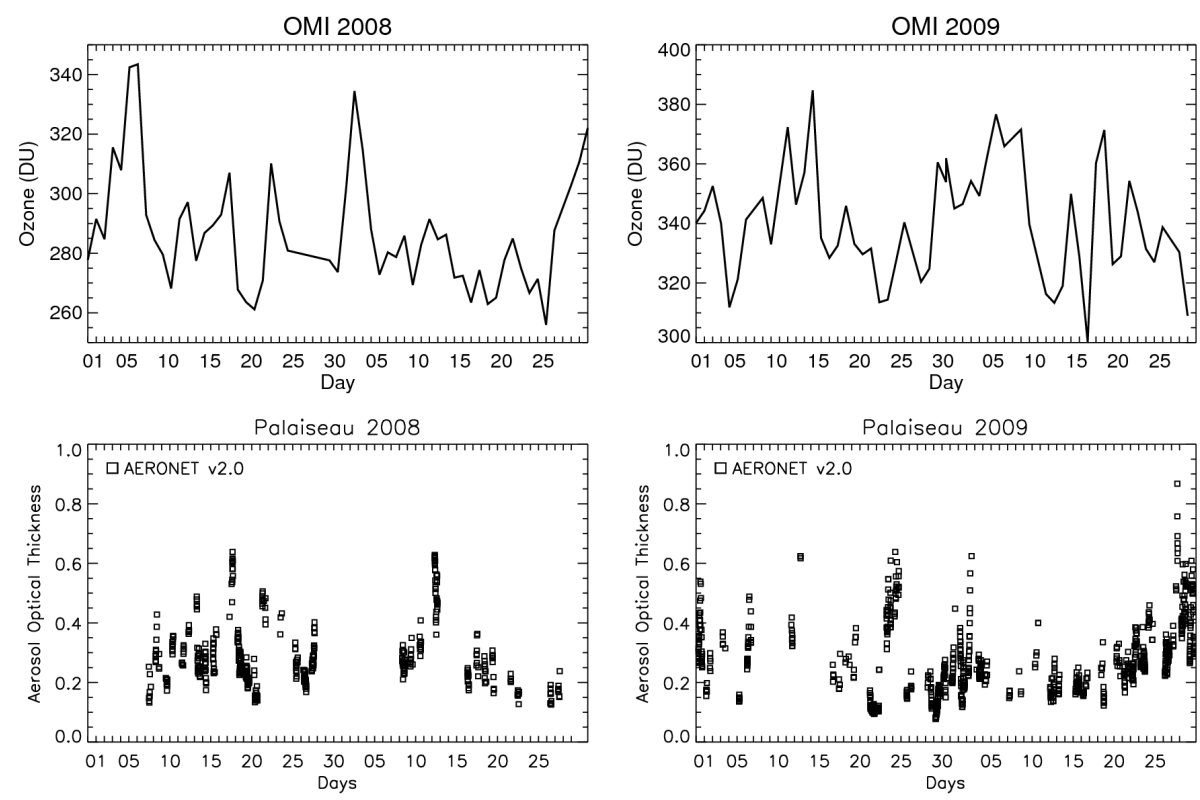

Fig. 1. Ozone (top) and aerosol optical thickness at $340 \mathrm{~nm}$ (bottom) during the RISC-UV 1 (left) and 2 (right) campaign over SIRTA observatory. Ozone and aerosol measurements are provided by the AURA/OMI and AERONET teams, respectively.

The current OMI surface UV algorithm applies no absorbing aerosol correction that overestimates the UVI in polluted region. The RISC-UV project is the opportunity to evaluate the model in a new urban situation where AOT variations are important. To improve the forecasts it is planned to use in the future the aerosol variables also computed in MOCAGE (see for instance, Martet et al., 2009) to impact on UVI calculations.

In a second step, the clear sky values are modified, depending upon cloudiness conditions. A simple cloud effect parametrisation, developed initially for the MOZART model (Brasseur et al., 1998), is used in MOCAGE. This cloud parametrisation considers the vertical profile of cloudiness available in the model to estimate the modification of the UV flux compared to the clear sky situation; it is expressed in the form of a ratio, which is in general smaller than 1.0 (except for radiation enhancement effects in the case of low zenith angle and low cloudiness). The cloudiness modification ratio is applied to the clear-sky values to provide the actual UV index. As illustrated in the following of the paper, the representation of cloud effects on UV index is currently a challenge in numerical forecasts. Firstly, there are issues regarding the quality of cloudiness forecasts in current numerical weather prediction models (Météo-France, ECMWF,...), which are often not enough realistic (both in timing and intensity). Secondly, the representation of cloud effects on radiation is also complex, particularly when aerosol scattering is important.

MOCAGE is used by Météo-France to provide operationally forecasts of UV indices since 2003. At variance with the results presented here for the purpose of model evalua- tion, these forecasts not only rely on the numerical output of MOCAGE, but use in fact human-expertised cloudiness to alter MOCAGE clear-sky estimates. Indeed, it has been found that the results are far more reliable than with the direct use of numerical prediction cloudiness. For this parameter, there is still a significant added value by human forecasters.

\subsection{TUV model}

The Tropospheric Ultraviolet-Visible Model (TUV) developed by Madronich and Flocke (1997) is used over the wavelength range $121-750 \mathrm{~nm}$, for calculating the spectral irradiance, the spectral actinic flux, photodissociation coefficients, and biologically effective irradiance. The code has a number of features including: separate direct and diffuse contributions, loading of weighting functions, variable wavelength and altitude grids, absorption by oxygen, ozone, nitrogen dioxide, sulphur dioxide and aerosols, scattering by air, clouds, and aerosols (Rayleigh and Mie).

The 4.1 version of the model is used to estimate the surface UV irradiances in clear-sky conditions during the two RISC-UV campaigns. The OMI products provide the input ozone, nitrogen dioxide, and sulphur dioxide columns. The aerosol optical properties are provided by the AERONET network. Figure 1 shows the total ozone column and the AOT at $340 \mathrm{~nm}$ variations over the SIRTA observatory. The albedo is assumed to be Lambertian, i.e., the reflected light is isotropic, and independent of direction of incidence of light, and is set to $3 \%$ at all wavelengths. The atmospheric pressure and temperature profiles are adjusted to the mid-latitude summer profile defined in Table 6 of Ellingson et al. (1991). 

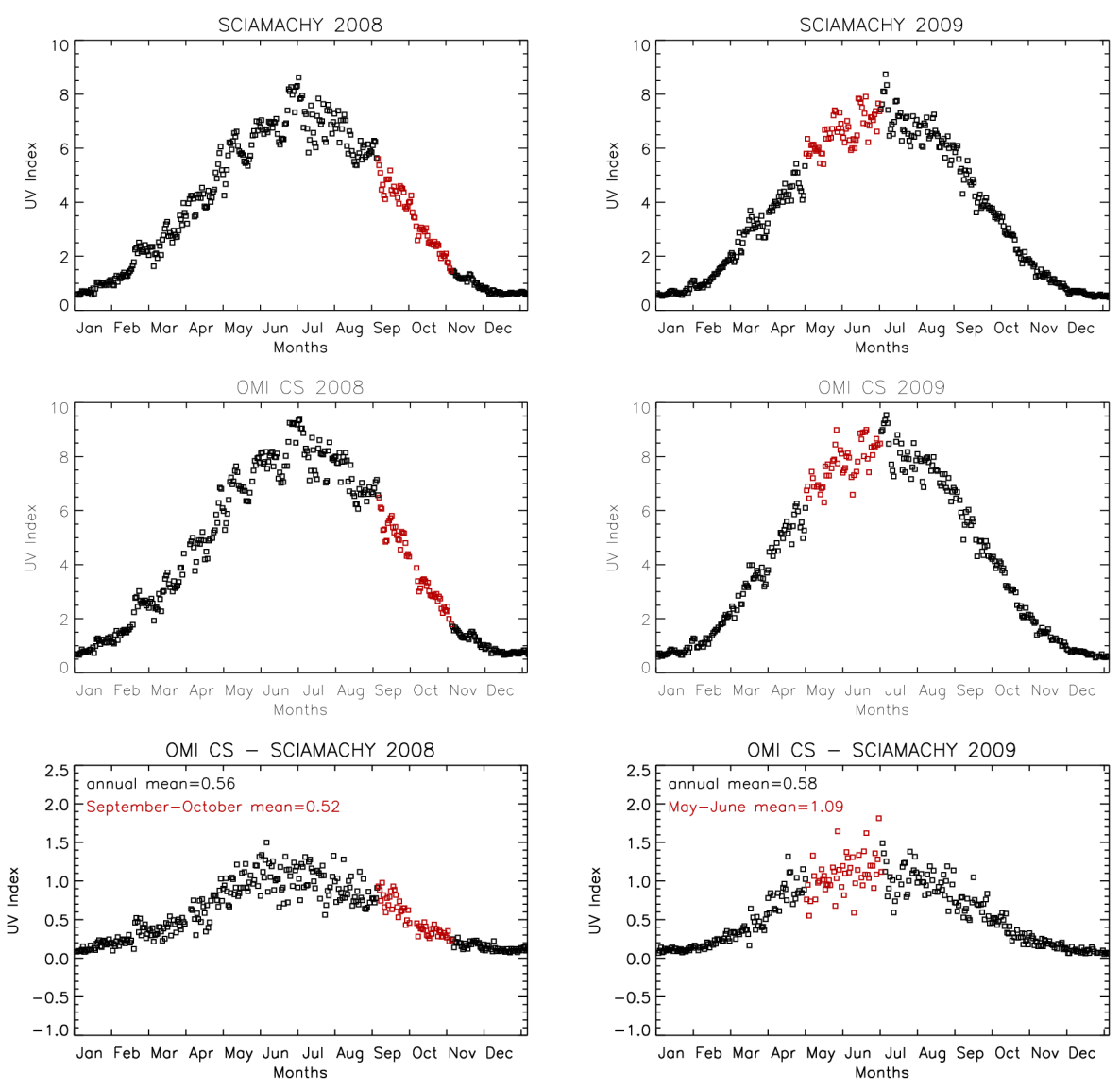

Fig. 2. SCIAMACHY and OMI (clear-sky data) satellite 2008 (left) and 2009 (right) UVI products. Bottom figures: absolute mean difference between OMI clear sky and SCIAMACHY products for 2008 (left) and 2009 (right). Red squares: RISC UV campaign periods.

All these observations and settings are used to calculate the typical variations of the clear-sky UVI during the campaigns (see Sect. 6.2). The clear-sky condition must be understood as 'no cloud' condition, but with aerosols.

\section{Temporal variation of $\mathrm{UV}$ radiation}

\subsection{Annual cycle}

This section is focused on the annual UVI cycle observed over the SIRTA observatory by the three satellite-borne instruments. Figure 2 shows the clear-sky products OMI-CS and SCIAMACHY, and Fig. 3 the all-sky products OMI and GOME-2 during 2008 and 2009. The absolute mean difference of the satellite products is also shown in Fig. 2 (bottom panel) and Fig. 3 only for 2009 year (bottom panel). A simple linear 2-D-interpolation was made in considering the nearest products to match the SIRTA location and to calculate the satellite noon values over the SIRTA observatory. The standard deviation in a $1^{\circ} \times 1^{\circ}$ lat-lon box centred on the SIRTA observatory is typically $0.2,0.3,0.6$, and $0.5 \mathrm{UVI}$, for the SCIAMACHY, OMI-CS, OMI and GOME-2 products, respectively. The two RISC-UV campaigns are highlighted in red. At the first glance is noticed the difference between the clear-sky products (SCIAMACHY, OM-CS) and the products retrieved with a realistic algorithm with cloud cover parametrisation (OMI, GOME-2). The variability in clear-sky conditions is 3 times weaker with typical standard deviation of 0.25 UVI. The larger variability and the maximum amplitude occur during the June-July transition.

The 2008 campaign (September-October) is not situated in this maximum period of variability, contrary to the 2009 campaign (May-June). In early summer, the variability over a week, due to changing zenith angle at noon in clearsky conditions does not exceed 2 UVI. The cloud effect increases this variability to 5 and 6 UVI for OMI and GOME2 , respectively. Differences in annual maximum amplitude are \pm 0.75 UVI, with $8.5,9.5,9$, and 8 UVI for SCIAMACHY, OMI-CS, OMI and GOME-2 annual maximum, respectively. The SCIAMACHY maximum is 1 UVI lower than OMI-CS. The same gap is found between GOME-2 maximum and OMI maximum. In all cases the annual minimum is stable around $0.5 \pm 0.25 \mathrm{UVI}$ on early January. The 

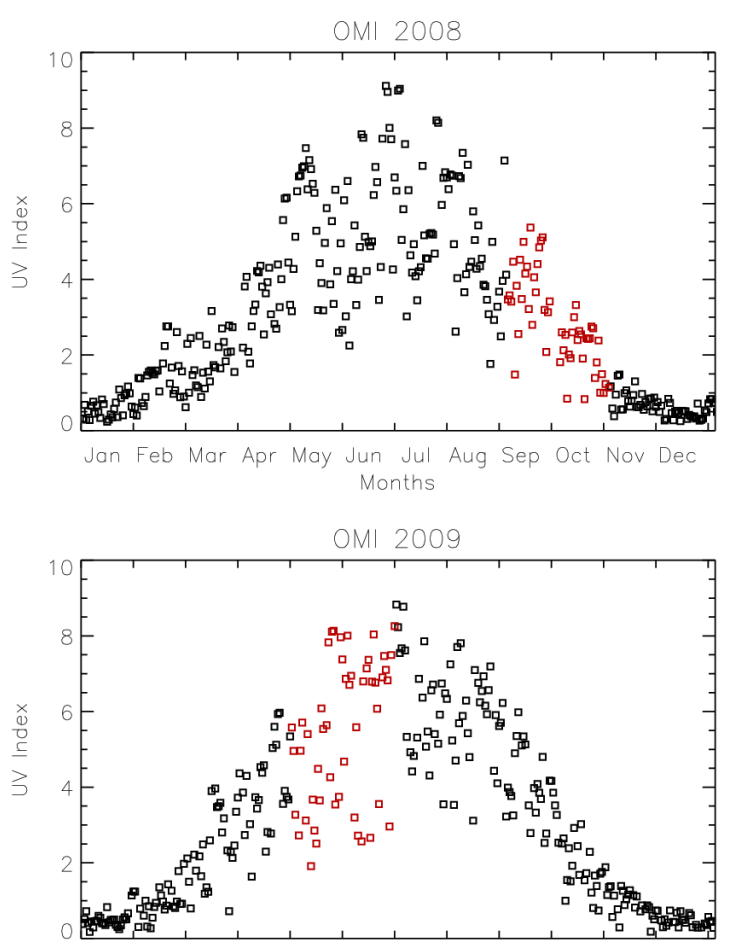

Jan Feb Mar Apr May Jun Jul Aug Sep Oct Nov Dec

Months
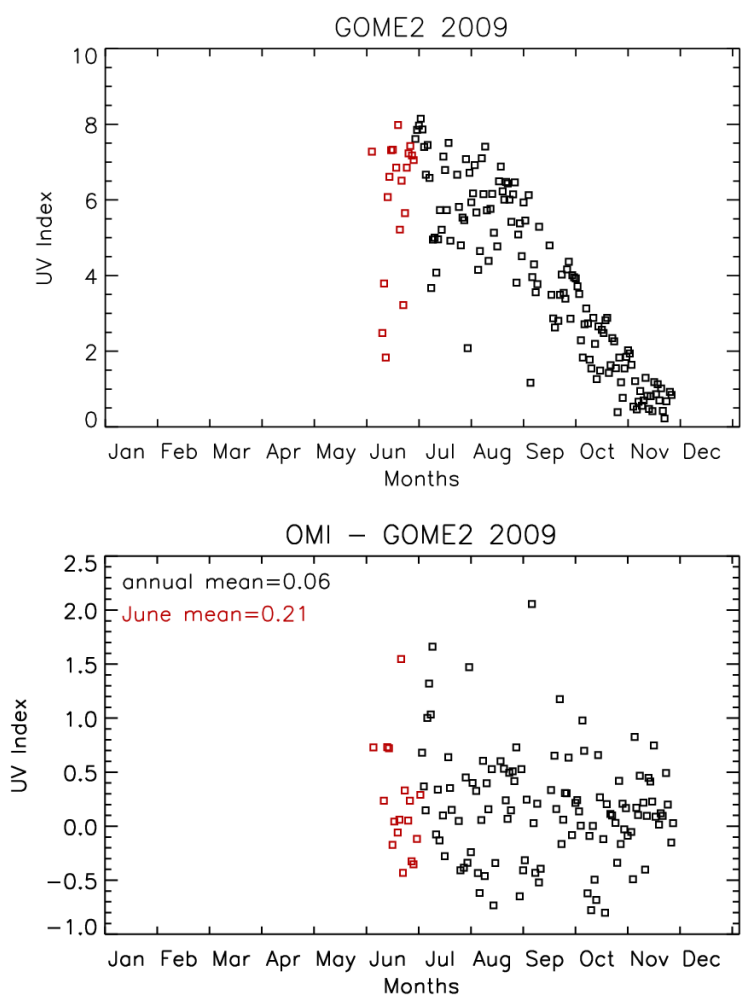

Fig. 3. OMI and GOME2 (all-sky data) satellite 2008 (top) and 2009 (middle) UVI products. Bottom figure: absolute mean difference between OMI and GOME2 products for 2009. Red squares: RISC UV campaign periods. difficulty to retrieve UVI essentially results from our capacity to well-reproduce the temporal and spatial variability of products influencing the UV surface radiation. A change in the ozone and/or aerosol amounts could create an offset of 1 to 2 UVI in the clear-sky UVI products. Similarly the cloud cover adds 2 or 3 times more pronounced rapid changes to the UVI products.

This comparison of the annual UVI cycle highlights a systematic annual bias of $\sim 0.6 \mathrm{UVI}$ in the OMI-CS products compared to the SCIAMACHY products (bottom panel of Fig. 2). This bias is dependent of the seasonal cycle with value of $\sim 0.52 \mathrm{UVI}$ in the September-October period and $\sim 1.1$ UVI in the May-June period. The absolute mean differences between OMI and GOME 2 from June to December 2009 (bottom panel of Fig. 3) highlight a good agreement between their products. No annual mean difference have been found between these two products. The mean difference in June, 2009 is only 0.2 UVI.

\subsection{Diurnal cycle}

Satellite data are local noon-values and do not allow to study the diurnal UVI cycle. Alternative comparisons with the SIRTA observations could be achieved to evaluate the ability of the MOCAGE model to reproduce this diurnal UVI cycle.

Figure 4 shows in colour lines, the diurnal cycle observed during the 2008 (top) and 2009 (bottom) campaigns by the instruments deployed at the SIRTA observatory (Pyrano-UVAE, Pyrano-UVB, Spectroradiometer, and Biometer). The black symbols represent the UVI products at noon of the space-borne instruments (OMI, OMI-CS, and SCIAMACHY). Finally, the diurnal cycles provided by the MOCAGE (black lines) and TUV (dash lines) models are plotted. For each campaign two days were selected to characterize the typical clear-sky and overcast conditions.

At first glance, all the SIRTA instruments are in good agreement over the two campaigns. During the clear-sky conditions (left figures) the SIRTA instruments show maxima \pm 0.5 UVI around the TUV maxima. The OMI and OMICS noon-values are naturally similar in clear-sky conditions. On 22 May 2009, the satellite noon-values compared to the TUV calculations show bias about +0.8 UVI for the OMI products and $-0.6 \mathrm{UVI}$ for the SCIAMACHY products. The MOCAGE maxima are $1 \pm 0.5$ lower than the TUV maxima during the clear-sky conditions despite the same total ozone columns from OMI. This discrepancy is the sign of a too strong cloud cover forecast in the MOCAGE model.

Figures on the right show examples of overcast conditions. These figures illustrate the difficulty to quantify the impact of the cloud variability on UV radiation either in retrieval algorithms or in model parametrisations. During 1 October 2008 a cloud cover of $91 \%$ was observed, with alternately clear-sky peaks and low values. Despite this large variability, the OMI noon-value and the MOCAGE diurnal cycle are 

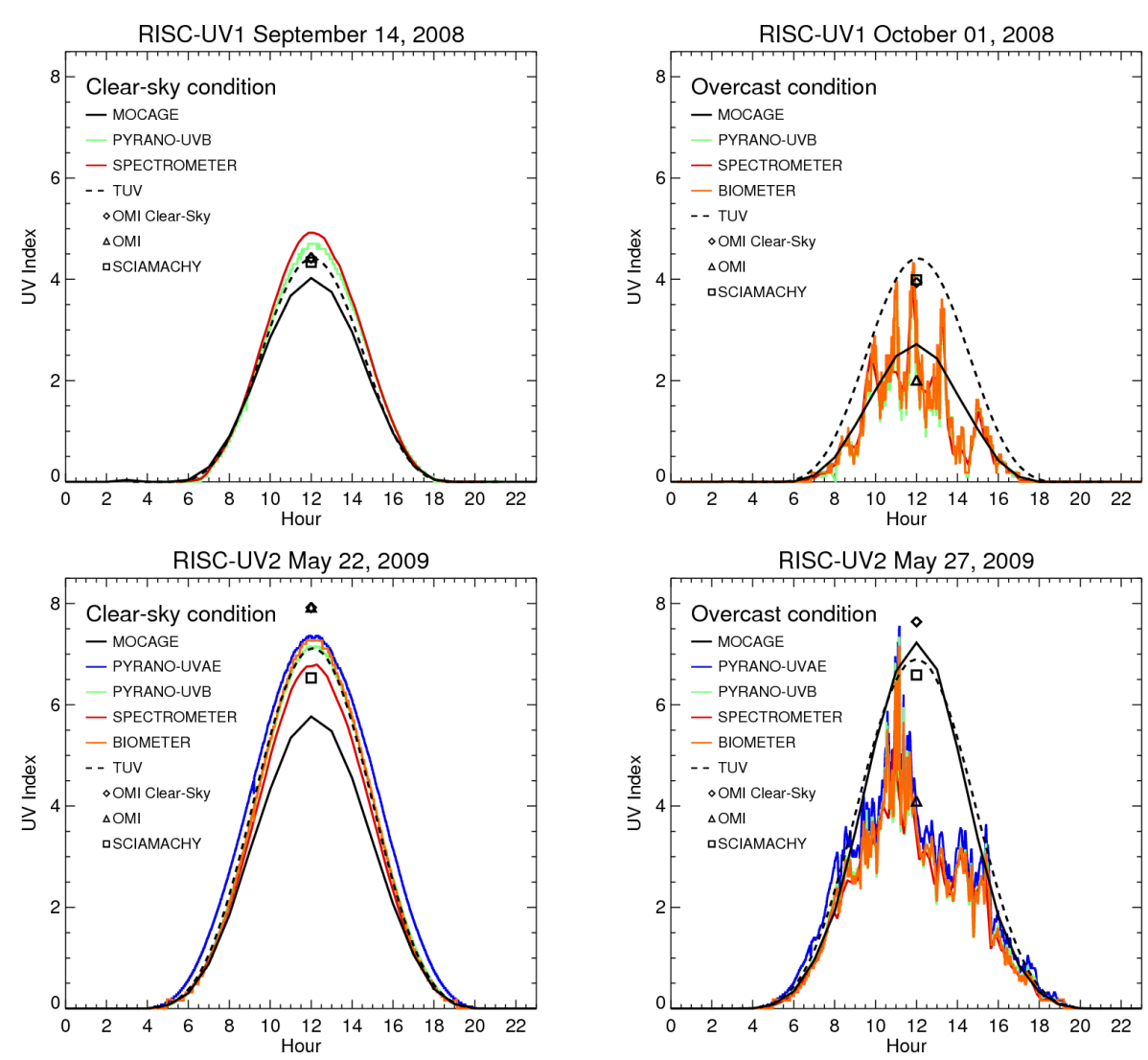

Fig. 4. Daily evolution of the UV index in clear-sky (left) and overcast (right) conditions during the RISC-UV campaign 2008 (top) and 2009 (bottom). MOCAGE simulation is compared to the SIRTA instruments (PYRANOMETER UVAE, PYRANOMETER UVB, SPECTROMETER, BIOMETER) and to the noon UV index values observed by the OMI (clear-sky and all-sky data) and SCIAMACHY (clear-sky data) instruments.

in good agreement with the mean diurnal cycle observed by the SIRTA instruments. This good result is not found during 27 May 2009 with a maximum cloud cover. The UVI are close to the clear-sky values during the beginning and the end of the diurnal cycle. The UVI from 8 a.m. to 3 p.m. (Local Time) deviated from the clear-sky situation with a typical background value of 3 UVI and a large peak between around $11 \mathrm{a}$ a.m. This peak is about 7.5 UVI, 0.8 UVI above the TUV calculation, and very close to the OMI-CS noon value. In this case, the noon-value observed by OMI and the SIRTA instruments are similar and around 4 UVI. Conversely, the MOCAGE simulation shows unrealistic clearsky values throughout the day. These examples highlight the dependence of the model to the quality of the cloud cover forecasts, in the ability to reproduce a realistic diurnal UVI cycle.

The OMI-CS products are in general higher than the TUV calculations with a positive bias evaluated to $1 \pm 0.3$ UVI. This discrepancy is not found in the SCIAMACHY products with difference lower than \pm 0.5 UVI. These satellite/groundbased comparisons show that OMI all-sky products are well appropriate to evaluate the UV-risk on health in providing
UVI close to the ground-based observations. No systematic underestimation or overestimation is detected in the OMI allsky products during typical cloud covers. The same overestimation found in the OMI-CS products is detected in the OMI all-sky products during clear-sky conditions.

\section{Comparisons with ground based data}

\subsection{Method}

As described in Sect. 2, all the retrieval algorithms do not systematically take into account the cloud effect on UV radiation. So, to investigate the quality of the satellite UVI products, a classification of the days as a function of the cloud cover was necessary. This classification applied to the RISC-UV periods on SIRTA observatory, is shown on the Fig. 5. A day is counted as "clear-sky", "cloudy", or "overcast" condition if the cloud cover is below $25 \%$, between 25 and $75 \%$, or larger than $75 \%$, respectively. Clear-sky conditions were not predominant during the campaigns. They represent only 22 and $13 \%$ of the observation in 2008 and 2009, 

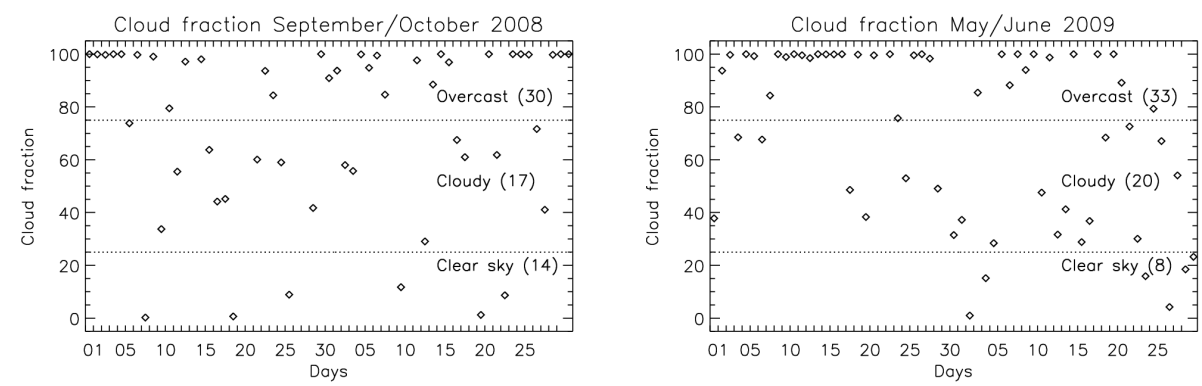

Fig. 5. Classification of the RISC UV periods (left: September-October 2008, right: May-June 2009) at noon in function of the cloud fractions: $0-25 \%$ clear sky, 25-75\% cloudy, 75-100\% overcast situations.

respectively; whereas the overcast condition represents about $52 \%$ of the observations. The very high temporal variability of the UVI is explained by broken cloud cover. In partially cloudy condition a variability of 4 UVI is usually measured within the same minute over the Parisian region in summer.

The SIRTA observatory also provides an altitude classification of the clouds : the low $(\leq 3 \mathrm{~km})$, the middle $(3-7 \mathrm{~km})$, and the high level clouds $(\geq 7 \mathrm{~km})$. This altitude classification is shown in Table 2 for the RISC-UV campaigns. High level clouds are more often observed in 2008 with $43 \%$ of the detections against $15 \%$ in 2009 . The cloud average altitudes in the May-June period are $400 \mathrm{~m}$ lower for low and middle level clouds and $850 \mathrm{~m}$ for high level clouds. The impact of the altitude of clouds is not evaluated in this article.

All the satellites provide a global spatial coverage with resolutions better than one degree corresponding to around $50 \mathrm{~km}$ of resolution. To compare these data with the SIRTA observations, we used a previously cited 2-D-interpolation technique to construct satellite fields over the SIRTA observatory. Statistical comparisons were conducted between all the databases at the noon values, to assess the reality of the UVI daily trends measured by the satellites and simulated by the MOCAGE model. The TUV model was previously used to provide a clear-sky UV reference state during the both campaigns.

\subsection{Clear-sky variability}

The TUV UVI simulation has been chosen as reference for clear-sky conditions. Figure 6 shows the evolution of the UV index when the cloud effect on UV radiation is absent. The variability is expected to be reduced, but not disappear due to the variability of atmospheric constituents influencing the UV radiation, present in the simulation. Variations in total ozone are mainly caused by variations in the amount of ozone in the lower stratosphere, where dynamical processes are a dominant source of the ozone changes over the short-time scales (few days). Variations in the aerosol loading are explained by tropospheric events like urban pollution or longtransported natural sources.
Table 2. Cloud altitudes detected over Palaiseau site during the RISC-UV campaigns. \#: number of observations when cloud altitudes could be defined. Mean and Std-Dev: mean and standard deviations of the cloud altitudes classified in three categories: low $(<3 \mathrm{~km})$, middle $(3-7 \mathrm{~km})$ and high level clouds $(>7 \mathrm{~km})$.

\begin{tabular}{lrrr}
\hline Sep-Oct 2008 & $\#$ & Mean $(\mathrm{m})$ & Std-Dev $(\mathrm{m})$ \\
\hline low & 51 & 1845 & 556 \\
middle & 80 & 4983 & 1279 \\
high & 102 & 9581 & 1522 \\
\hline May-Jun 2009 & $\#$ & Mean (m) & Std-Dev (m) \\
\hline low & 274 & 1455 & 759 \\
middle & 104 & 4503 & 1317 \\
high & 71 & 8735 & 1319 \\
\hline
\end{tabular}

With this model-controlled environment, the UVI trends are -2.5 and 1.2 per month during the September-October 2008 and May-June 2009 periods, respectively. In these periods, the mean ozone columns are 270 DU (SeptemberOctober 2008) and 330 DU (May-June 2009), and the total ozone changes are about $90 \mathrm{DU}$, representing about $30 \%$ of the mean values. AOT also shows a large variability during the two campaigns with values ranging predominantly from 0.1 to 0.6 with the same 0.2 background value. Ozone and AOT time-dependent concentrations (Fig. 1) highlight 1 or 2 pronounced peaks a month, corresponding to events in the low stratosphere for ozone and in the low troposphere for aerosols.

The daily variabilities of ozone and aerosols have a direct impact on the retrieved UV index. For example, when the ozone column changed from $384 \mathrm{DU}$ on 15 May 2009 to 300 DU on 17 June 2009, the clear-sky UVI changed from 4.9 to 7.4. The AOT was similar around 0.3 during these two days. So, a decrease of 30-35 DU in the ozone amount leads to an increase of 1 UVI. Variations greater than 2 UVI could be explained by total ozone change in the 2009 campaign. The AOT variations over the SIRTA observatory were too low to investigate their impact on UVI. 
Table 3. Statistics for the RISC-UV campaigns. \#: number of measurements. $r$ : Pearson's correlation coefficient. $\rho$ : Spearman's rank correlation coefficient. $\Delta(\mathrm{UVI}), \Delta(\%)$ : absolute and relative mean difference (standard deviation into brackets) with spectrometer chosen as reference. $A$ and $B$ : linear regression coefficients using a "robust" least absolute deviation method $(y=A+B x)$. RMSD: root mean square difference between the instruments and the spectrometer chosen as reference.

\begin{tabular}{lrrrrrrrr}
\hline Instruments & $\#$ & $r$ & $\rho$ & $\Delta(\mathrm{UVI})$ & $\Delta(\%)$ & $A$ & $B$ & RMSD \\
\hline Pyranometer UVAE & 36 & 0.91 & 0.78 & $0.05(0.78)$ & $0.9(14.5)$ & -0.01 & 1.03 & 0.77 \\
Pyranometer UVB & 49 & 0.96 & 0.96 & $-0.10(0.47)$ & $-2.5(9.4)$ & -0.02 & 0.98 & 0.48 \\
Biometer & 28 & 0.96 & 0.91 & $0.15(0.56)$ & $4.3(14.9)$ & -0.17 & 1.10 & 0.57 \\
Dosimeter & 09 & 0.91 & 0.80 & $-0.83(0.53)$ & $-15.0(9.1)$ & -0.35 & 0.94 & 0.96 \\
SIRTA & 60 & 0.95 & 0.93 & $-0.03(0.59)$ & $-0.8(11.5)$ & -0.06 & 1.02 & 0.59 \\
OMI-CS & 05 & 0.99 & 1.00 & $0.77(0.26)$ & $12.8(3.6)$ & 0.06 & 1.14 & 0.81 \\
OMI & 58 & 0.89 & 0.87 & $0.19(0.92)$ & $6.0(25.2)$ & -0.13 & 1.06 & 0.93 \\
SCIAMACHY & 09 & 0.98 & 0.95 & $-0.17(0.29)$ & $-2.7(5.2)$ & 0.59 & 0.87 & 0.33 \\
GOME-2 & 13 & 0.91 & 0.79 & $0.18(0.79)$ & $5.7(14.0)$ & 0.49 & 0.95 & 0.78 \\
MOCAGE $^{1}$ & 66 & 0.62 & 0.59 & $0.51(1.66)$ & $20.0(62.9)$ & 0.24 & 0.93 & 1.72 \\
MOCAGE $^{2}$ & 33 & 0.91 & 0.85 & $-0.30(0.80)$ & $-7.2(15.5)$ & -1.30 & 1.13 & 0.84 \\
MOCAGE $^{3}$ & 09 & 0.99 & 0.93 & $-0.96(0.21)$ & $-18.8(6.2)$ & -0.73 & 0.95 & 0.78 \\
\hline
\end{tabular}

${ }^{1}$ all-sky conditions, ${ }^{2}$ cloudy and clear-sky condtion, ${ }^{3}$ clear-sly conditions.
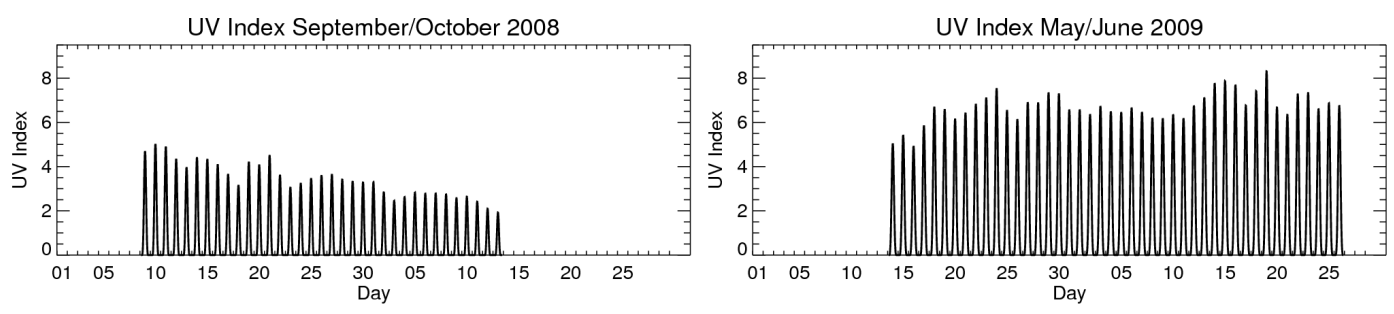

Fig. 6. TUV calculations of the UV index during the RISC-UV 1 (left) and 2 (right) campaign over Palaiseau in clear-sky conditions.

These last results are just an overview of the dependence between ozone, aerosols and surface UVI. A more robust multivariate analysis, able to investigate a non-linear dependence, is necessary to separate the different contributions.

\subsection{Statistical comparisons}

The ability of the satellites to monitor the UV risk on health could be investigated with daily comparisons. Figure 7 shows the temporal comparisons between the satellite products, the MOCAGE simulations and the mean values of three SIRTA instruments and the spectroradiometer observations. These daily evolutions were statistically evaluated in using correlations and histograms. The statistical coefficients are presented in Table 3.

The correlations between the spectroradiometer and the other instruments are also shown on Fig. 8 for both campaigns. The top left figure shows that the SIRTA instruments and the spectrometer are well correlated with a mean Pearson's coefficient $(r)$ of 0.95 and a Spearman's coefficient $(\rho)$ of 0.93 . The dosimeter shows a slightly worse correlation with $r=0.91$ and $\rho=0.80$. The mean difference between the spectroradiometer and the SIRTA instruments is -0.03 UVI with a RMSD of 0.59 UVI. The dosimeter is less performing as expected, with an absolute difference of -0.83 UVI and a RMSD of 0.96 UVI. These results characterize the accuracy of the professional and low-cost UV instruments to about $0.5 \mathrm{UVI}$ and $1 \mathrm{UVI}$, respectively. Variability under these thresholds is not significant. A deeper analysis between research-grade and consumer-products UV instruments can be found in Corrêa et al. (2010).

The correlations with the OMI and GOME-2 products (the two bottom figures on the left) are as good as the dosimeter correlation with $r$ about 0.9 . These products present a slight positive bias of $0.2 \mathrm{UVI}$ and a RMSD of 0.9 UVI comparable to the biometer instrument. These statistics show that the OMI and GOME-2 observations provided UVI products with quality equivalent to ground-based instruments and could be used to evaluate the UV risk on health.

The OMI-CS and SCIAMACHY statistics have been calculated only during clear-sky conditions reducing the number of comparisons. But the correlations stay significant with a positive Student's test. Comparisons show excellent $r$ coefficients about 0.98 , mean differences of 0.8 and 

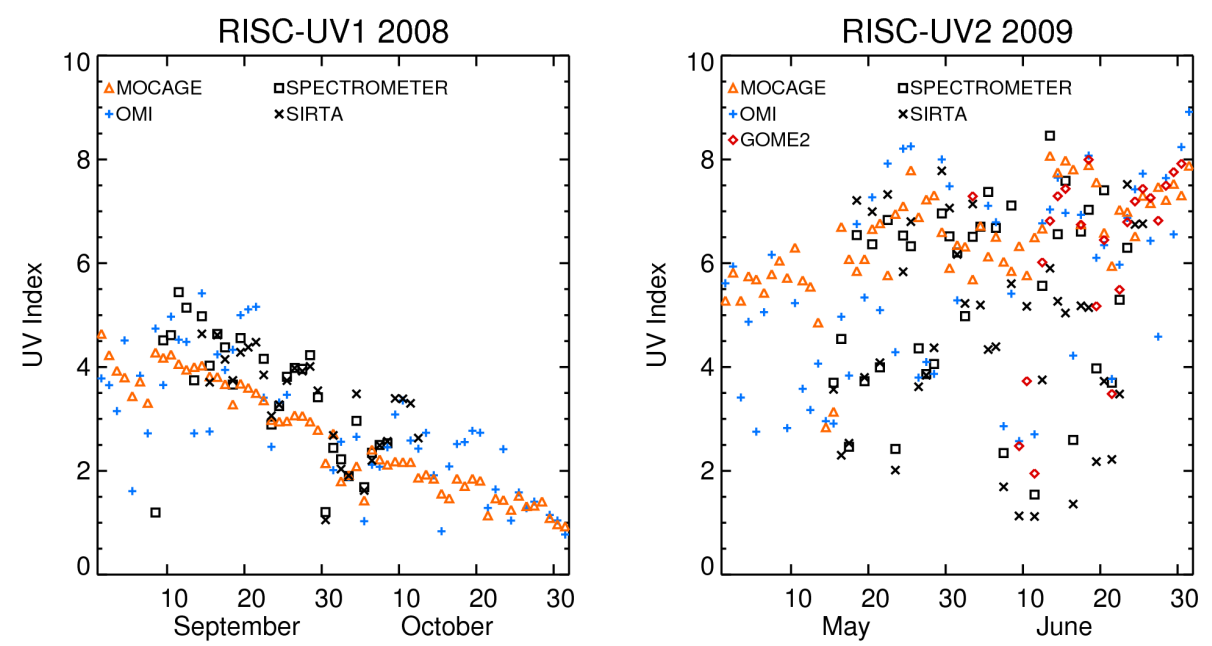

Fig. 7. Comparisons between satellite UVI products (OMI, GOME2), the MOCAGE model, the spectrometer and the average of the SIRTA instruments (pyranometer UVAE, pyranometer UVB, biometer) during the 2008 (left) and the 2009 (right) campaigns.

-0.2 UVI, and RMSD of 0.8 and 0.3 UVI, for OMI-CS and SCIAMACHY, respectively. The clear-sky products show similar good statistics compared to the SIRTA instruments.

MOCAGE correlations have been calculated in three situations: (1) all-sky, (2) clear-sky and cloudy, and (3) clearsky conditions. $0.62,0.91$ and $0.99 r$ coefficients have been found for the (1), (2) and (3) situations, respectively (cf. Table 3). The $r$ coefficient decreases with increasing cloud cover. This behaviour is the evidence of an inefficient parametrisation of the cloud cover in the model. In situation (1), the MOCAGE data show a positive bias (0.51 UVI) and a large RMSD (1.72 UVI). In situation (3) the MOCAGE data show correlation similar to the OMI-CS products, but with a negative bias of $\sim 1$ UVI and a RMSD of 0.8 .

Unfortunately a complete statistic analysis could not been achieved as a function of the cloud covers defined on the Fig. 5. The observations in overcast conditions are not sufficient to calculate significant statistics. Nevertheless, to have an idea of this dependence, a colour code is used on the Fig. 8 based on cloud cover information retrieved from ancillary SIRTA instruments: blue (clear-sky), light-blue (partially cloudy) and red (overcast). The three figures on the right show satellite clear-sky products and MOCAGE simulation where poor correlations are found with overcast conditions. The left figures show the reference SIRTA observations and the satellite products where cloud cover are taken into account in a more realistic way. In these cases the satellite correlations (OMI and GOME-2) are closed to the SIRTA correlations even in overcast conditions.

Figure 9 is another view of the comparisons with the spectroradiometer. In this figure histograms are used to quantify the precision of the other instruments with the spectroradiometer. The histograms represent the frequency of values (in percent) which deviated from the spectroradiometer observations. The deviations are expressed in percent and the observations are binned with $10 \%$ intervals. The figure shows on the left the SIRTA instrument histograms and on the right the satellites and MOCAGE histograms. The number of observations is added on the top right figures. The arithmetic averages are overplotted with dashed lines to highlight the characteristics of the distributions.

The broadband instruments (Pyrano-UVAE, Pyrano-UVB, Biometer) show Gaussian distributions centred near zero with a dispersion below $10 \%$. The dosimeter shows a distribution centred around $-15 \%$ with the same dispersion. This low bias creates a slight underestimation of the UV risk which has to be confirmed. The dosimeter is a good low-cost instrument available to evaluate UV risk on health and make recommendations in direction to the general public (Mahé et al., 2011).

The histograms of clear-sky products are well-centred with a negative bias of $3 \%$ for SCIAMACHY and a positive bias of $13 \%$ for OMI-CS. The MOCAGE histogram shows a positive tail of distribution which shifts the mean value to $20 \%$ away from the maximum value around $-15 \%$. This feature is explained by the difficulty to forecast the overcast conditions. Some days with overcast condition were wrongly diagnosed and replaced by periods with increased UVI. In the OMI product no high bias and positive tail of distribution are found. The GOME-2 data show a similar well-centred histogram. These last histograms centred around $5 \%$ for OMI and GOME-2, are close to the SIRTA histograms distributions. This is a new evidence of the good quality of the OMI and GOME-2 products to evaluate the UV-risk on health.

\section{Cloud effect on UV radiation}

Statistical comparisons highlighted the importance to correctly estimate the cloud effect on the amount of surface UV 

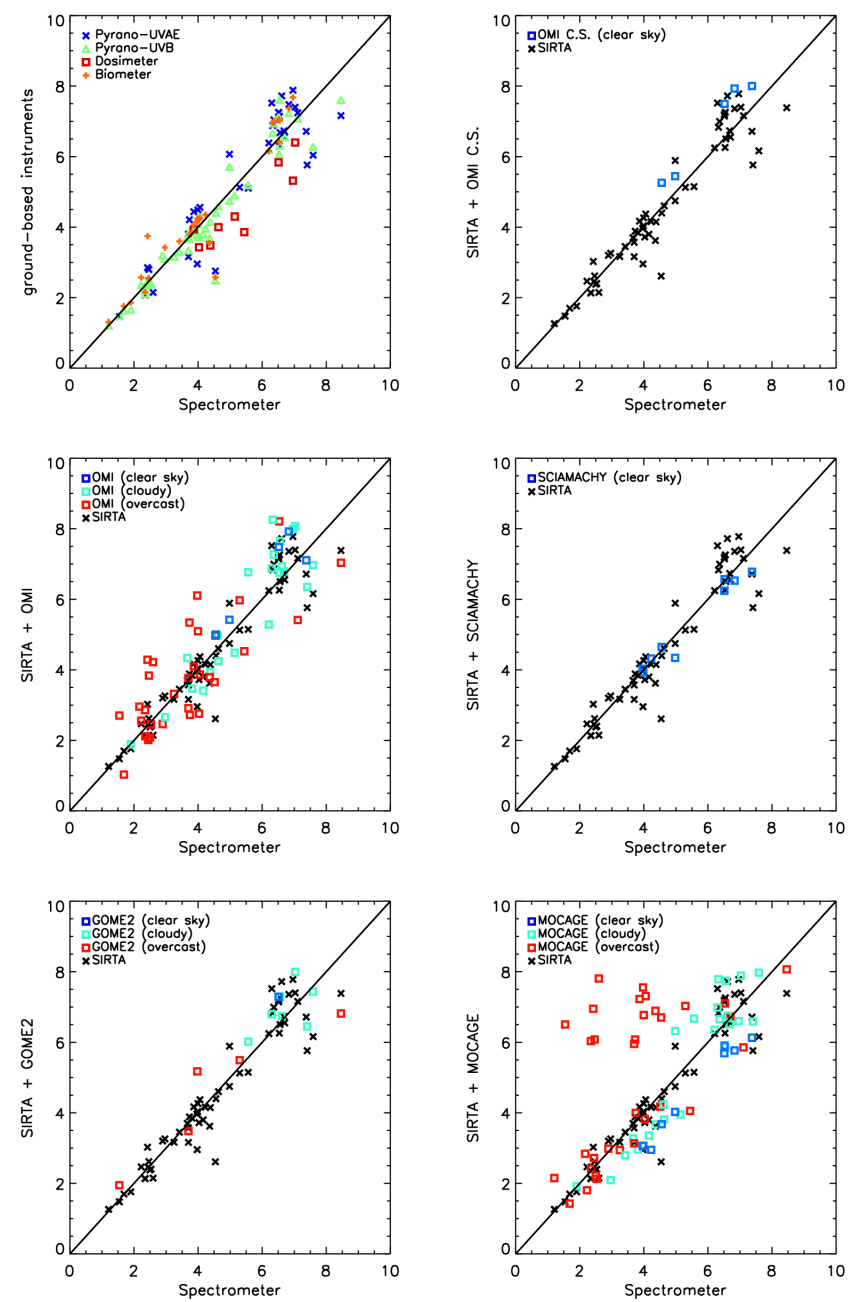

Fig. 8. From top left to bottom right: correlations between UVI spectrometer observations and the ground-based instruments, the OMI, the GOME2, the OMI-CS, the SCIAMACHY, and MOCAGE products over the RISC-UV campaigns. Correlation between the mean value of the SIRTA instruments (Pyranometer UVAE, Pyranometer UVB, Biometer) and the spectrometer have been systematicaly overplotted (black cross). In few panels a cloud color classification has been used to evaluate the correlation in function of the cloud coverage (red: overcast, clear blue: cloudy, blue: clear sky conditions).

radiation. Many questions are generated from these results. How much overcast conditions reduce the UVI? Is the cloud effect always negative? Figure 10 tries to answer these questions through the evolution of the UV index as a function of the cloud cover. The measured values are normalized by the TUV clear-sky outputs (see Fig. 6). This representation has the advantage to be independent on the climatic variability (ozone, aerosols, $\mathrm{NO}_{2}, \mathrm{SO}_{2}$ ) or solar zenith angles. The figures show the evolution of the individual data and the data binned with octal intervals usually used in meteorology. During clear-sky conditions such a ratio is theoreti-
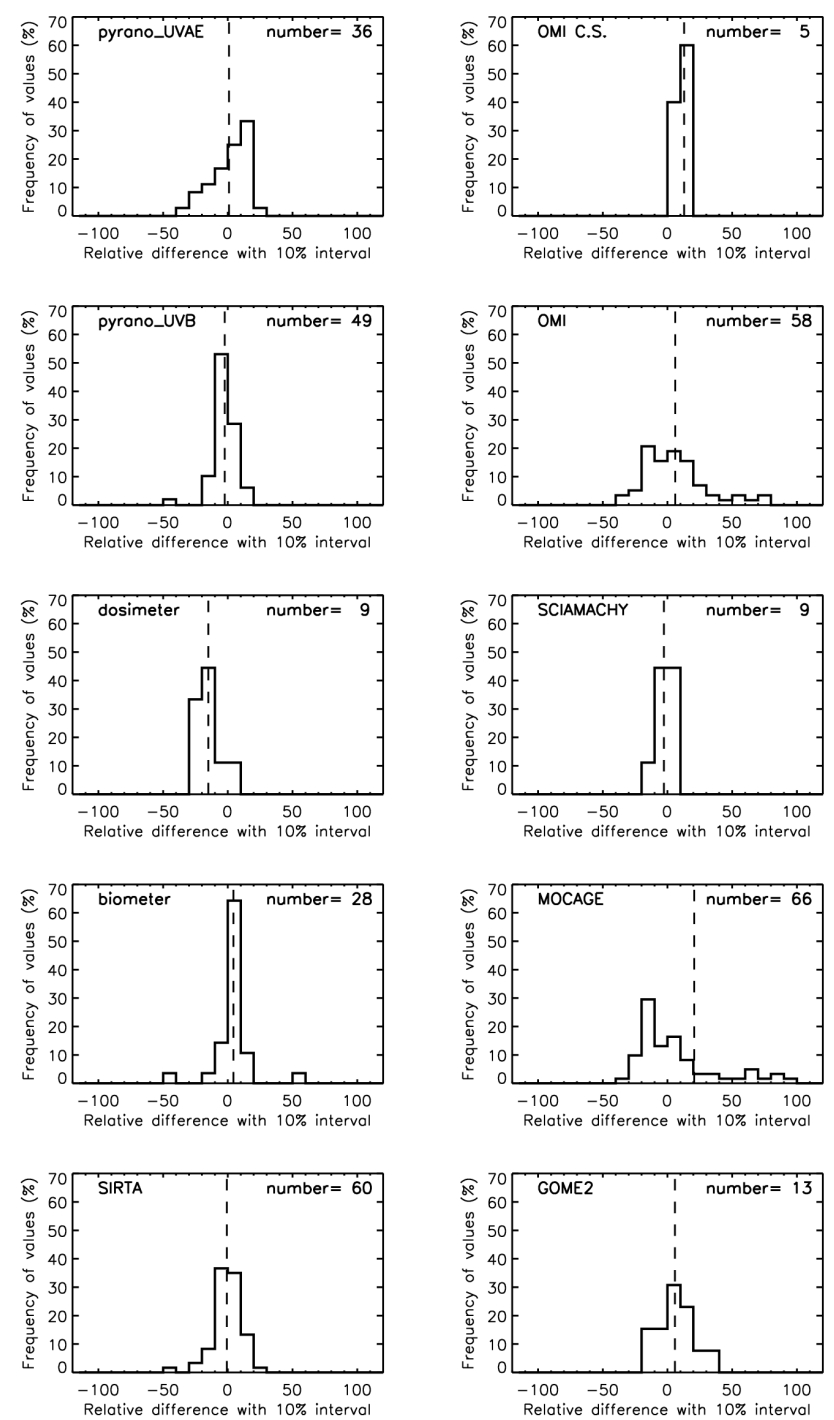

Fig. 9. The histograms represent the frequency of values (in percent) which deviated from the spectrometer observations. The deviations are expressed in percent and the observations are binned with $10 \%$ intervals. The figure shows on the left the SIRTA instruments histograms and on the right the satellites and MOCAGE histograms. The number of observations is added on the top right figures. The arithmetic averages are overplotted with dashed lines to highlight the characteristics of the distributions.

cally close to unity and decreases when clouds appear. The left figure shows the evolution of the UVI measured at noon by the spectroradiometer, the SIRTA instruments (PyranoUVAE, Pyrano-UVB, biometer), the GOME-2 and OMI instruments and the MOCAGE model. The middle and right figures show the same data plotted in octal intervals.

The SIRTA observations are represented with two black symbols (cross: SIRTA instruments, square: spectroradiometer). Their evolutions are very similar with ratio near unity in clear-sky condition, a first 0.85 minimum around $25 \%$ 

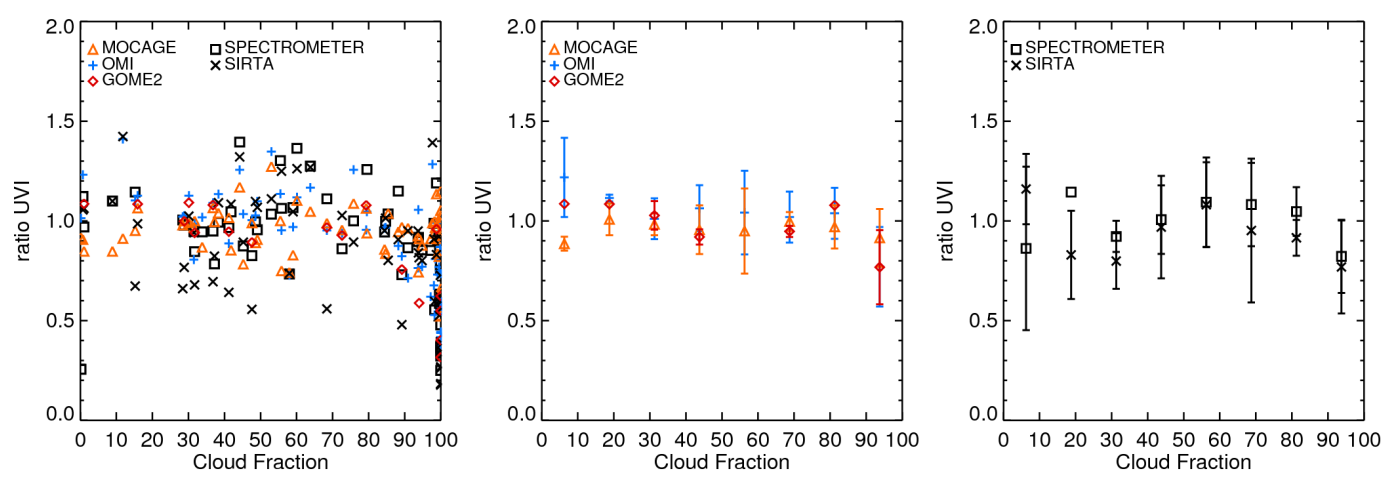

Fig. 10. Evolution of the ratio of the UVI observed and modelled to the UVI modelled on clear-sky conditions with the TUV model, as a function of the cloud coverage. Comparisons between satellite UVI products (OMI, GOME2), MOCAGE model, spectrometer and the average of SIRTA instruments (pyranometer UVAE, pyranometer UVB, biometer) during RISC-UV campaigns for individual data (left) and data binned in octal intervals (middle and right). The error bars shown in the middle and right panels represent \pm one standard deviation of the binned data.

cloud cover, a 1.1 maximum around $65 \%$ and a 0.55 second minimum in overcast condition. The data reveal a $10 \%$ UVI enhancement in broken cloud conditions (near $65 \%$ cloud cover) compared to the clear-sky conditions, a result also found by other studies (e.g. Shafer et al., 1996; Pachart et al., 1999). To explain this result it is important to detail the origin of surface UV radiation.

In clear-sky situations UV radiation is partitioned in a direct, unscattered, component and a diffuse component, mostly scattered by molecules. Some scattering occurs also due to aerosols. In presence of clouds, scattering increases due to reflections on cloud edges, hence increasing the diffuse component and reducing the direct component of UV radiation when the sun is hidden. In low cloud cover conditions the increase of diffuse radiation is not sufficient to compensate the decrease of the direct component. So, the UVI decrease from clear-sky condition until a cloud cover of about $25 \%$. From this threshold to a cloud cover of $65 \%$, the situation reverses and the diffuse radiation lead to an increase in UVI. In situations of significant broken cloud cover, i.e. between $50 \%$ and $80 \%$, the average amount of direct and diffuse radiations becomes up to $10 \%$ larger than the clear-sky value. When approaching overcast conditions the direct component of radiation vanishes completely, resulting in UVI about half of clear-sky values.

The OMI and GOME-2 measurements show a clear-sky value around 1.2 and 1.1, and a progressive decreasing to 0.6 and 0.5 . The satellite measurements do not show a wellpronounced wave-like sharp, which indicates that the UV radiation reflected by clouds are not taken into account. The MOCAGE data show a 0.9 mean course with a 1.0 maximum around $25 \%$. The second maximum around $65 \%$, present in the ground-based data, is not present in the MOCAGE simulations. This result confirms that the cloud effect is not sufficiently taken into account into the MOCAGE model.

\section{Discussion}

Studies of the impact of UV radiation on health, require knowledge of UV climatology and changes that have occurred in the past. It is necessary to have the estimates of average and extreme characteristics of the UV impact as well as doses over different periods, for a long time in the past. Since the climatic conditions are highly variable, UV climatologies with high spatial resolutions are needed. To get UV irradiances in the past, modelling of UV irradiances is the only possibility, using adequate data for the atmospheric parameters which are of relevance for the UV. A separation of the determined trend change of the UV radiation, as a result of change of total ozone or cloudiness was necessary to reveal sources of temporal variations of the UV trend patterns. The results will give the basis for research on skin cancer development since this has such a long incubation period with the consequence that measured instantaneous UV data are not meaningful.

Different efforts have been made to create such UV climatologies. The European COST 726 project (European Cooperation in Science and Technology) provided erythemal daily doses over Europe $\left(30^{\circ} \mathrm{N}-80^{\circ} \mathrm{N}, 25^{\circ} \mathrm{E}-35^{\circ} \mathrm{W}\right)$ with a $1^{\circ} \times 1^{\circ}$ spatial resolution for the period 1958-2002 (COST726, 2009a, b). The climatology of the erythemal daily doses created by Lee-Taylor et al. (2010) have been calculated with the TUV model by using the ozone column database observed by the TOMS (Total Ozone Mapping Spectrometer) instruments onboard the Nimbus-7, Meteor-3 and Earth Probe satellites for the period 1979-2000. The cloud and aerosol effects have been taken into account through the $380 \mathrm{~nm}$ reflectivity observed by the instrument. The French laboratory Mines ParisTech has developed the HELIOSAT model to convert satellite METEOSAT observations into global surface radiations gathered in the HélioClim database (available on the SoDa website: Solar Irradiation 
Database http://www.soda-is.com). This database is used in the framework of the European project EUROSUN to evaluate the erythemal dose over Europe. The HéliClim1 database provides daily data from 1985 to 2005 (Cros et al., 2004). Since February 2004, the second generation of METEOSAT satellites have been launched, with improving temporal $(15 \mathrm{~min})$ and spatial $(3 \mathrm{~km}$ to the equator) resolutions. It was the opportunity to create the HélioClim 3 from February 2004 to present. Archives of the UV radiation monitoring products from MSR measurements (SCIAMACHY and GOME satellites Multi-Sensor Reanalysis), are available on the TEMIS website (Tropospheric Emission Monitoring Internet Service, http://www.temis.nl). Data are available between 1 November 1978 and 31 December 2008. A recent climatology of global UV irradiance was created by Herman (2010) from satellite measurements (Nimbus 7/TOMS, SBUV-2 series, Earth-Probe/TOMS, SeaWIFS and OMI) from 1979 to 2008. All these climatologies will be a new source of information for epidemiologists to evaluate the UV-risk on health.

Coupled Climate Chemistry models like MOCAGE (but in a different configuration than the one used here, as described in Teyssèdre et al., 2007) provide predictions of surface UV radiation influencing factors allowing the simulation of surface UV levels from the past to present, but also in the coming decades (WMO, 2007; Eyring et al., 2007; Tourpali et al., 2009). Under cloud free conditions, surface erythemal irradiance has been calculated to decrease globally as a result of the projected stratospheric ozone recovery at rates that are larger in the first half of the 21st century and smaller towards its end. Between 2000 and 2100 the decrease over midlatitudes ranges between 5 and $15 \%$, while at the southern high latitudes the decrease is twice as much. Since effects from changes in cloudiness, surface reflectivity and tropospheric aerosol loading, have not been considered, over some areas the actual changes in future UV radiation may be different depending on the evolution of these parameters. According to the IPCC Fourth Assessment Report (IPCC, 2007), multimodel simulations based on the SRESA1B scenario suggest that cloud cover will decrease by the end of the 21 st century in most of the low and middle latitudes of both hemispheres by up to $4 \%$ (Meehl et al., 2007; Tourpali et al., 2009). This would result in an increase in surface UV radiation in these regions (e.g. by about $4 \%$ for erythemal irradiance), counteracting the decrease from ozone recovery. The opposite is expected in high latitudes and in a few low-latitude regions where cloud cover is predicted to increase. The projected UV changes have large uncertainties due to the approximations inherent in the assumptions for cloudiness, aerosols and surface albedo.

\section{Conclusions}

The RISC-UV campaigns have been conducted in September-October 2008 and May-June 2009 in the strongly urbanized Parisian region. These campaigns were the opportunity for a scientific collaboration between a medical community concerned by the problems relative to the UV exposure and atmospheric physicists interested in the evolution of the surface solar radiation in relation to environmental changes. This article focused on the evaluation of the satellite instruments and a Chemistry and Transport Model capacity to provide good UVI necessary for a more responsible public health policy.

In this paper, the MOCAGE Chemistry and Transport Model developed in France by the CNRM laboratory (Météo-France) and the OMI, SCIAMACHY and GOME-2 instruments are compared. The TUV model was additionally used to provide a reference clear-sky climatology. This intercomparison has confirmed the well-known difficulty to take into account the great temporal and spatial variability of cloud cover into retrieval algorithms or models. Such a challenge is sometimes avoided by providing only clear-sky data, which is in general an upper limit estimate of the UV index (and can be useful in terms of exposure risk management). In general, the strategy to implement the cloud cover into validated codes depends essentially on the available cloud databases.

The MOCAGE model use a cloud parametrisation developed initially for the MOZART model. CMF are calculated and applied to the clear-sky situations. Unfortunately, the result is too close to the clear-sky condition to be useful. The overcast condition is especially unrealistic. A further investigation is needed to find the reason of this discrepancy. A first improvement will consist in taking into account the aerosol distribution also computed in MOCAGE in the UVI calculations. But the insufficient quality of current numerical weather prediction models cloudiness forecasts could be the main origin of the gap between the modelling and the RISCUV observations. The discrepancy is more pronounced in the second campaign in May-June 2009, where annual cloud variability is maximum. In September-October 2008, the monthly UV diurnal cycle is well-simulated. On the other hand, in early summer the high temporal cloud variability seems to be smoothed in the MOCAGE model. Overcast conditions are replaced by partially cloudy situations that lead to an overestimation of the UVI. A better representation of cloudiness variability and intensity would improve greatly the forecasts of UV indices particularly in the summer period. The results shown here confirm the choice of Météo-France to currently rely on human forecasted cloudiness rather than on numerical predictions for public information on UV levels. This study has also pointed out that MOCAGE model and OMI products despite of using the same two-step technique, do not come to the same conclusion in terms of cloud cover. The investigation of this discrepancy 
and its correction will strongly improve the UV model forecasts.

The satellite UV observations are also dependent on the knowledge of the cloud cover. The OMI surface UV algorithm first estimates the clear-sky surface irradiance, and next this irradiance is multiplied by a factor that accounts for the attenuation of UV radiation by clouds and nonabsorbing aerosols. For SCIAMACHY observations, a cloud cover correction is only applied to calculate the daily UV dose. For Europe the daily UV dose is computed by using, cloud cover fraction data from METEOSAT and for global UV dose fields, the ISCCP cloud database is used to provide monthly average erythemal UV dose data. In the GOME-2 algorithm, the cloud optical depth is estimated from AVHRR/3 reflectances. The sampling of the diurnal cloud cycle is improved by using additional AVHRR data from the NOAA satellites. So, different strategies to implement the cloud modification factor either in retrieval algorithms or models was developed with different success. In terms of CMF, the satellite products do not reproduce the wave-like evolution of the CMF found in the RISC-UV data with a low maximum near $65 \%$ of cloud cover and a quick UV decreasing in overcast conditions. Nevertheless the OMI and GOME-2 products with a low 0.2 UVI positive bias are adequate for monitoring the UV-risk on health. In the case of the GOME-2 comparisons, a longer common period should be necessary to confirm the good quality of the data. The retrieval algorithm could be improved with a more realistic cloud cover, which is the only way to proper weighting of the UV direct and indirect UV radiation.

In order to make sensible choices on sun exposure, the public needs more understandable information. The public needs knowledge of the UV environment as it relates to sunburn and to vitamin D production. Currently, the necessary information is not generally available to the public. In the case when UV information is available (e.g. in France by Météo-France), new agencies and newspapers broadcast this information only during the summer period. Further, often only the peak daily value is provided. This is because the UVI was originally designed only to give the risk of skin damage. When the UVI is 3, skin damage occurs after approximately $1 \mathrm{~h}$, but sufficient vitamin $\mathrm{D}$ can still be produced in a few minutes provided face, arms and legs are exposed (McKenzie et al., 2009). For the public to be able to make informed decisions about appropriate solar behaviour to avoid skin damage in summer and vitamin D deficiency in winter, it is essential that they have access to UV information throughout the year, throughout the day, and for all sky conditions. Only satellite observations with high spatial and temporal resolutions enable the medical community to provide this public service in near real-time. The RISCUV project was the opportunity to show that this challenge is now possible: UV monitoring can be done by using satellite products (OMI, GOME-2) and UV forecasts can be made by using modelling as long as cloud forecasts and the parametri- sation of the impact of cloudiness on UV radiation are adequate.

Efforts are still necessary to elaborate an efficient general public health policy about risks or benefits of UV radiation. The RISC-UV project has shown that it is necessary to improve the consideration of the parameters influencing the UV radiations (aerosols, cloud covers, etc) in the UVI calculations. Recommendations made from these UVI have to be easily understood by the general public. To achieve this issue efforts will be necessary in the education of the general public (in school, in media, etc). In France such effort is in progress, especially in the schools via the program "Vivre avec le soleil" (Bense et al., 2009).

Acknowledgements. The authors thank the GIS-CLIMAT organisation for their financial support, the METEO-FRANCE colleagues for their collaborations. We thank the O3M SAF project of the EUMETSAT, the OMI International Science Team and the Tropospheric Emission Monitoring Internet Service (TEMIS) project, part of the Data User Programme (DUP) of the European Space Agency (ESA) for providing satellite data.

Edited by: B. Mayer

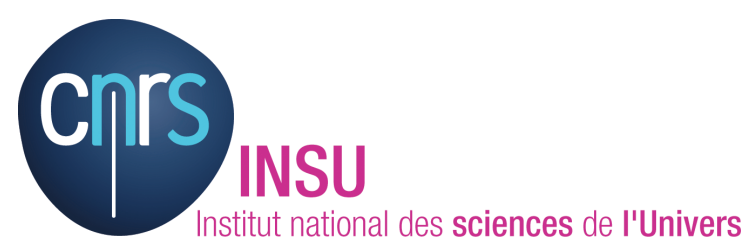

The publication of this article is financed by CNRS-INSU.

\section{References}

Allaart, M., van Weele, M., Fortuin, P., and Kelder, H.: An Empirical model to predict the UV-index based on Solar Zenith Angle and Total Ozone, Meteorol. Appl. (Roy. Meteorol. Soc.), 11, 5965, doi:10.1017/S1350482703001130, 2004

Arola, A., Kazadzis, S., Lindfors, A., Krotkov, N., Kujanpaa, J., Tamminen, J., Bais, A., di Sarra, A., Villaplana, J. M., Brogniez, C., Siani, A. M., Janouch, M., Weihs, P., Webb, A., Koskela, T., Kouremeti, N., Meloni, D., Buchard, V., Auriol, F., Ialongo, I., Staneck, M., Simic, S., Smedley, A., and Kinne, S.: A new approach to correct for absorbing aerosols in OMI UV, Geophys. Res. Lett., 36, L22805, doi:10.1029/2009GL041137, 2009.

Bense D., Blanquet E., Cesarini P., Wilgenbus D.: Vivre avec le soleil : activités cycle 3 - Guide de l'enseignant, passerelle - sciences, santé, citoyenneté collection, Hatier edition, 2009.

Bousserez, N., Attié, J.-L., Peuch, V.-H., Michou, M., Pfister, G., Edwards, D., Avery, M., Sachse, G., Browell, E., and Ferrare, E.: Evaluation of MOCAGE chemistry and transport model during the ICARTT/ITOP experiment, J. Geophys. Res., 112, D120S42, doi:10.1029/2006JD007595, 2007.

Brasseur, G. P., Hauglustaine, D. A., Walters, S., Rasch, R. J., Müller, J.-F., Granier, C., and Tie, X. X.: MOZART, a global 
chemical transport model for ozone and related chemical tracers 1. Model descript ion, J. Geophys. Res., 103, 28265-28289, doi:10.1029/98JD02397, 1998.

Buchard, V., Brogniez, C., Auriol, F., Bonnel, B., Lenoble, J., Tanskanen, A., Bojkov, B., and Veefkind, P.: Comparison of OMI ozone and UV irradiance data with ground-based measurements at two French sites, Atmos. Chem. Phys., 8, 4517-4528, doi:10.5194/acp-8-4517-2008, 2008.

Buntoung, S. and Webb, A. R.: Comparison of erythemal UV irradiances from Ozone Monitoring Instrument (OMI) and groundbased data at four Thai stations, J. Geophys. Res., 115, D18215, doi:10.1029/2009JD013567, 2010.

Chubarova, N. E.: Influence of aerosol and atmospheric gases on ultraviolet radiation in different optical conditions including smoky mist of 2002, Dokl. Earth Sci., 394, 62-67, 2004.

Corrêa, M. P., Godin-Beekmann, S., Haeffelin, M., Brogniez, C., Verschaeve, F., Saiag, P., Pazmino, A., and Mahé, E.: Comparison between UV index measurements performed by researchgrade and consumer-products instruments, Photochem. Photobiol. Sci., 9, 459-463, 2010.

COST 726, Lityńska, Z., Koepke, P., De Backer, H., Gröbner, J., Schmalwieser, A., and Vuilleumier, L.: COST 726: Final report of COST action 726 Long term changes and climatology of UV radiation over Europe, COST Earth System Science and Environmental Management, Luxemburg: Office for Official Publications of the European Communities, 137 pp., 2009a.

COST 726, Lityńska, Z., Schmalwieser, A. W., Bais, A., Ettler, K., Gröbner, J., Köpke, P., Krzyścin, J., den Outer, P., Verdebout, J., Zipoli, G., and Biszczuk-Jakubowska, J.: Booklet: UV radiation and life, COST Earth System Science and Environmental Management, Luxemburg: Office for Official Publications of the European Communities, 52 pp., 2009 b.

Cros, S., Albuisson, M., Lefevre, M., Rigollier, C., and Wald, L.: HelioClim: a long-term database on solar radiation for Europe and Africa, in: Proceedings of Eurosun 2004, published by PSE GmbH, Freiburg, Germany, 916-920, ISBN 3-9809656-4-3, 2004.

Courtier, P., Freydier, C., Geleyn, J.-F., Rabier, F., and Rochas, M.: The Arpege project at Météo-France, Proceedings of the 1991 ECMWF seminar, ECMWF, 193-231, 1991.

de Laat, A. T. J., van der A, R. J., Allaart, M. A. F., van Weele, M., Benitez, G. C., Casiccia, C., Paes Leme, N. M., Quel, E., Salvador, J., and Wolfram, E.: Extreme sunbathing: Three weeks of small total $\mathrm{O}_{3}$ columns and high UV radiation over the southern tip of South America during the 2009 Antarctic $\mathrm{O}_{3}$ hole season, Geophys. Res. Lett., 37, L14805, doi:10.1029/2010GL043699, 2010.

Dufour, A., Amodei, M., Ancellet, G., and Peuch, V.-H.: Observed and modelled "chemical weather" during ESCOMPTE, Atmos. Res., 74, 161-189, 2004.

El Amraoui, L., Attié, J.-L., Semane, N., Claeyman, M., Peuch, V.H., Warner, J., Ricaud, P., Cammas, J.-P., Piacentini, A., Josse, B., Cariolle, D., Massart, S., and Bencherif, H.: Midlatitude stratosphere troposphere exchange as diagnosed by MLS $\mathrm{O}_{3}$ and MOPITT CO assimilated fields, Atmos. Chem. Phys., 10, 21752194, doi:10.5194/acp-10-2175-2010, 2010.

Ellingson, R. G., Ellis, J., and Fels, S.: The intercomparison of radiation codes used in climate models: long wave results, J. Geophys. Res., 96, 8929-8953, 1991.
Eskes, H. J., Van Velthoven, P. F. J., Valks, P. J. M., and Kelder, H. M.: Assimilation of GOME total ozone satellite measurements in a three-dimensional tracer transport model, Q. J. Roy. Meteorol. Soc., 129, 1663-1681, 2003.

Eyring, V., Waugh, D. W., Bodeker, G. E., Cordero, E., Akiyoshi, H., Austin, J., Beagley, S. R., Boville, B. A., Braesicke, P., Brühl, C., Butchart, N., Chipperfield, M. P., Dameris, M., Deckert, R., Deushi, M., Frith, S. M., Garcia, R. R., Gettelman, A., Giorgetta, M. A., Kinnison, D. E., Mancini, E., Manzini, E., Marsh, D. R., Matthes, S., Nagashima, T., Newman, P. A., Nielsen, J. E., Pawson, S., Pitari, G., Plummer, D. A., Rozanov, E., Schraner, M., Scinocca, J. F., Semeniuk, K., Shepherd, T. G., Shibata, K., Steil, B., Stolarski, R. S., Tian, W., and Yoshiki, M.: Multi-model projections of stratospheric ozone in the 21st century, J. Geophys. Res., 112, D16303, doi:10.1029/2006JD008332, 2007.

Gröbner, J., Blumthaler, M., Kazadzis, S., Bais, A., Webb, A., Schreder, J., Seckmeyer, G., and Rembges, D.: Quality assurance of spectral solar UV measurements: results from $25 \mathrm{UV}$ monitoring sites in Europe, 2002 to 2004, Metrologia, 43, 6671, 2006.

Haeffelin, M., Barthès, L., Bock, O., Boitel, C., Bony, S., Bouniol, D., Chepfer, H., Chiriaco, M., Cuesta, J., Delanoë, J., Drobinski, P., Dufresne, J.-L., Flamant, C., Grall, M., Hodzic, A., Hourdin, F., Lapouge, F., Lemaître, Y., Mathieu, A., Morille, Y., Naud, C., Noël, V., O'Hirok, W., Pelon, J., Pietras, C., Protat, A., Romand, B., Scialom, G., and Vautard, R.: SIRTA, a ground-based atmospheric observatory for cloud and aerosol research, Ann. Geophys., 23, 253-275, doi:10.5194/angeo-23-253-2005, 2005.

Herman, J. R.: Global increase in UV irradiance during the past 30 years (1979-2008) estimated from satellite data, J. Geophys. Res., 115, D04203, doi:10.1029/2009JD012219, 2010.

Hollingsworth, A., Engelen, R. J., Textor, C., Benedetti, A., Boucher, O., Chevallier, F., Dethof, A., Elbern, H., Eskes, H., Flemming, J., Granier, C., Morcrette, J. J., Rayner, P., Peuch, V.-H., Rouil, L., Schultz, M., and Simmons, A.: The Global Earth-system Monitoring using Satellite and in-situ data (GEMS) Project: Towards a monitoring and forecasting system for atmospheric composition, B. Am. Meteorol. Soc., 89(8), 1147-1164, doi:10.1175/2008BAMS2355.1, 2008.

ICNIRP (International Commission on Non-Ionizing Radiation Protection): Guidelines on limits of exposure to ultraviolet radiation of wavelengths between $180 \mathrm{~nm}$ and $400 \mathrm{~nm}$ (incoherent optical radiation), Health Phys., 87, 171-186, 2004.

IPCC (Intergovernmental Panel on Climate Change), Climate Change 2007: The Physical Science Basis. Contribution of Working Group I to the Fourth Assessment Report of the Intergovernmental Panel on Climate Change, edited by: Solomon S., Qin, D., Manning, M., Chen, Z., Marquis, M., Averyt, K. B., Tignor, M., and Miller, H. L., Cambridge University Press, Cambridge, UK and New York, NY, USA, 2007.

Josse, B., Simon, P., and Peuch, V.-H.: Rn-222 global simulations with the multiscale CTM MOCAGE, Tellus, 56B, 339-356, 2004.

Kalakoski, N.: $\mathrm{O} 3 \mathrm{M}$ SAF validation report, ref:SAF/O3M/FMI/VR/OUV/O01, issue: 1/2009, EUMETSAT, Finish Meteorological Institute, Finland, 58 pp., 2009.

Kazadzis, S., Bais, A., Arola, A., Krotkov, N., Kouremeti, N., and Meleti, C.: Ozone Monitoring Instrument spectral UV irradiance products: comparison with ground based measurements 
at an urban environment, Atmos. Chem. Phys., 9, 585-594, doi:10.5194/acp-9-585-2009, 2009.

Kinne, S.: Towards an observation-tied AOD climatology, presentation in AT2 Aerosol Workshop, Bremen, Germany, June 2007.

Krotkov, N. A., Bhartia, P. K., Herman, J. R., Fioletov, V., and Kerr, J.: Satellite estimation of spectral surface UV irradiance in the presence of tropospheric aerosols 1: Cloud-free case, J. Geophys. Res., 103, 8779-8793, 1998.

Krotkov, N. A., Herman, J. R., Bhartia, P. K., Fioletov, V., and Ahmad, Z.: Satellite estimation of spectral surface UV irradiance 2. Effects of homogeneous clouds and snow, J. Geophys. Res., 106, 11743-11759, 2001.

Krotkov, N. A., Herman, J. R., Bhartia, P. K., Seftor, C., Arola, A., Kaurola, J., Taalas, P., and Vasilkov, A.: OMI Surface UV Irradiance Algorithm, Algorithm Theoretical Baseline Document: Clouds, Aerosols, and Surface UV Irradiance, edited by: Stammes, P., Vol. III, ATBD-OMI-03, Version 2.0, August 2002.

Kujanpää, J.: O3M SAF Offline UV Product, Algorithm Theoretical Basis Document, ref: SAF/O3M/FMI/ATBD/001, issue: 1.2, EUMETSAT, Finish Meteorological Institute, Finland, 15 pp., 2008.

Lee-Taylor, J., Madronich, S., Fischer, C., and Mayer, B.: A Climatology of UV Radiation, 1979-2000, $65^{\circ} \mathrm{S}-65^{\circ} \mathrm{N}$, Chapter 1 in UV Radiation in Global Climatic Change: Measurements, Modeling and Effects on Ecosystems, edited by: Gao, W., Schmoldt D., and Slusser, J. R., Springer-Verlag and Tsinghua Unisersity Press, 2010

Levelt, P. F., Hilsenrath, E., Leppelmeier, G. W., Van den Oord, G. H. J., Bhartia, P. K., Tamminen, J., De Haan, J. F., and Veefkind, J. P.: The Ozone Monitoring Instrument, IEEE T. Geosci. Remote Sens., 44(5), 1093-1101, 2006.

Lefèvre, F., Brasseur, G. P., Folkins, I., Smith, A. K., and Simon, P.: Chemistry of the 1991-1992 stratospheric winter: threedimensional model simulations, J. Geophys. Res., 99, 81838195,1994

Madronich, S. and Flocke, S.: Theoretical estimation of biologically effective UV radiation at the Earth's surface, in: Solar Ultraviolet Radiation - Modeling, Measurements and Effects, edited by: Zerefos, C., NATO ASI Series Vol. I52, SpringerVerlag, Berlin, Germnay, 1997.

Mahé, E., Beauchet, A., Corrêa, M. P., Godin-Beekman, S., Haeffelin, M., Bruant, S., Fay-Chatelard, F., Jégou, F., Saiag, P., and Aegerter, P.: Outdoor sports and risk of UV-related skin lesions in children: evaluation of risks, and prevention, British Journal of Dermatology, 165, 2, 360-367, doi:10.1111/j.13652133.2011.10415.x, 2011.

McKenzie, R. L., Liley, J. B., and Björn, L. O.: UV radiation: balancing risks and benefits, Photochem Photobiol, JanuaryFebruary; 85(1), 88-98, 2009.

McKinley, A. and Diffey, B. L.: A reference action spectrum for ultraviolet induced erythema in human skin, in: Human Exposure to Ultraviolet Radiaton: Riskes and Regulations, edited by: Passchier, W. F. and Bosnajakovic, B. F. M., International Congress Series, 8387 pp., Elsevier, Amsterdam, The Netherlands, 1987.

Martet, M., Peuch, V.-H., Laurent, B., Marticorena, B., and Bergametti, G.: evaluation of long-range transport and deposition of desert dust with the CTM Mocage, Tellus, 61B, 449-463, 2009.

Meehl, G. A., Stocker, T. F., Collins, W. D., Friedlingstein, P., Gaye, A. T., Gregory, J. M., Kitoh, A., Knutti, R., Murphy, J. M., Noda,
A., Raper, S. C. B., Watterson, I. G., Weaver, A. J., and Zhao, Z.-C.: Global Climate Projections, in: Climate Change 2007: The Physical Science Basis, Contribution of Working Group I to the Fourth Assessment Report of the Intergovernmental Panel on Climate Change, edited by: Solomon, S., Qin, D., Manning, M., Chen, Z., Marquis, M., Averyt, K. B., Tignor, M., and Miller, H. L., Cambridge University Press, Cambridge, UK and New York, NY, USA, 99, 2007.

Pachart, E., Lenoble, J., Brogniez, C., Masserot, D., and Bocquet, J. L.: Ultraviolet spectral irradiance in the French Alps. Results of two campaigns, J. Geophys. Res., 104, 16777-16784, 1999.

Rouil, L., Honoré, C., Vautard, R., Beekmann, M., Bessagnet, B., Malherbe, L., Méleux, F., Dufour, A., Elichegaray, C., Flaud, J.M., Menut, L., Martin, D., Peuch, A., Peuch, V.-H., and Poisson, N.: PREV'AIR: an operational forecasting and mapping system for air quality in Europe, B. Am. Meteorol. Soc., 90, 73-83, doi:10.1175/2008BAMS2390.1, 2008.

Shafer, J. S., Saxena, V. K., Wenny, B. N., Barnard, W., and De Luisi, J. J.: Observed influence of clouds in ultraviolet-B radiation, Geophys. Res. Lett., 23, 2625-2628, 1996.

Stockwell, W. R., Kirchner, F., Kuhn, M., and Seefeld, S.: A new mechanism for regional atmospheric chemistry modelling, J. Geophys. Res., 102, 25847-25879, 1997.

Tanskanen, A.: Lambertian surface albedo climatology at $360 \mathrm{~nm}$ from TOMS data using moving time-window technique. Proc. XX Quadrennial Ozone Symposium, 1-8 June, Kos, Greece., 1159-1160, 2004.

Tanskanen, A., Lindfors, A., Määattä, A., Krotkov, N., Herman, J., Kaurola, J., Koskela, T., Lakkala, K., Fioletov, V., Bernhard, G., McKenzie, R., Kondo, Y., O’Neill, M., Slaper, H., den Outer, P., Bais, A. F., and Tamminen, J.: Validation of daily erythemal doses from Ozone Monitoring Instrument with groundbased UV measurement data, J. Geophys. Res., 112, D24S44, doi:10.1029/2007JD008830, 2007.

Teyssèdre, H., Michou, M., Clark, H. L., Josse, B., Karcher, F., Olivié, D., Peuch, V.-H., Saint-Martin, D., Cariolle, D., Attié, J.-L., Nédélec, P., Ricaud, P., Thouret, V., van der A, R. J., VolzThomas, A., and Chéroux, F.: A new tropospheric and stratospheric Chemistry and Transport Model MOCAGE-Climat for multi-year studies: evaluation of the present-day climatology and sensitivity to surface processes, Atmos. Chem. Phys., 7, 58155860, doi:10.5194/acp-7-5815-2007, 2007.

Tourpali, K., Bais, A. F., Kazantzidis, A., Zerefos, C. S., Akiyoshi, H., Austin, J., Brühl, C., Butchart, N., Chipperfield, M. P., Dameris, M., Deushi, M., Eyring, V., Giorgetta, M. A., Kinnison, D. E., Mancini, E., Marsh, D. R., Nagashima, T., Pitari, G., Plummer, D. A., Rozanov, E., Shibata, K., and Tian, W.: Clear sky UV simulations for the 21 st century based on ozone and temperature projections from Chemistry-Climate Models, Atmos. Chem. Phys., 9, 1165-1172, doi:10.5194/acp-9-1165-2009, 2009.

van Geffen, J., van der A, R., van Weele, M., Allaart, M., and Eskes, H.: Surface UV radiation monitoring based on GOME and SCIAMACHY, Proceedings of the ENVISAT and ERS Symposium, 6-10 September 2004, Salzburg, Austria, ESA publication SP-572, 2005.

Williamson, D. L. and Rash, P. J.: Two-dimensional semilagrangian transport with shape-preserving interpolation, Mon. Weather Rev., 117, 102-129, 1989. 
World Health Organisation (WHO), Global Solar UV Index: A practical Guide, available online at: http://www.who.int/uv/ publications/en/GlobalUVI.pdf, 2002.
World Meteorological Organization (WMO), Scientific assessment of ozone depletion: 2006, Global Ozone Research and Monitoring Project Report No. 50, Geneva, Switzerland, 2007. 